\title{
Poly(A) site selection in the HIV-1 provirus: inhibition of promoter-proximal polyadenylation by the downstream major splice donor site
}

\author{
Mark P. Ashe, Philip Griffin, William James, and Nick J. Proudfoot \\ Sir William Dunn School of Pathology, University of Oxford, Oxford OX1 3RE, UK
}

\begin{abstract}
In common with all retroviruses, the human immunodeficiency virus type 1 (HIV-1) contains duplicated long terminal repeat (LTR) sequences flanking the proviral genome. These LTRs contain identical poly(A) signals, which are both transcribed into RNA. Therefore, to allow efficient viral expression, a mechanism must exist to either restrict promoter-proximal poly(A) site use or enhance the activity of the promoter-distal poly(A) site. We have examined the use of both poly(A) sites using proviral clones. Mutation of the previously defined upstream activatory sequences of the $3^{\prime}$ LTR poly(A) site decreases the efficiency of polyadenylation when placed in competition with an efficient downstream processing signal. However, in the absence of competition, these mutations have no effect on HIV-1 polyadenylation. In addition, the $5^{\prime}$ LTR poly(A) site is inactive, whereas a heterologous poly(A) site positioned in its place is utilized efficiently. Furthermore, transcription initiating from the $3^{\prime}$ LTR promoter utilizes the $3^{\prime}$ LTR poly(A) signal efficiently. Therefore, the main determinant of the differential poly(A) site use appears to be neither proximity to a promoter element in the 5' LTR nor the presence of upstream activating sequences at the 3' LTR. Instead, we show that the major splice donor site that is immediately downstream of the 5' LTR inhibits cleavage and polyadenylation at the promoter-proximal site. The fact that this poly(A) site is active in a proviral clone when the major splice donor site is mutated suggests that the selective use of poly(A) signals in HIV-1 is mediated by a direct inhibition of the HIV-1 poly(A) site by downstream splicing events or factors involved in splicing.
\end{abstract}

[Key Words: Poly(A) site selection; HIV-1 provirus; promoter-proximal site; polyadenylation; cleavage; downstream splicing events]

Received August 21, 1995; revised version accepted October 6, 1995.

The process of reverse transcription in retroviruses requires that the RNA genome contains terminally redundant ends and creates long terminal repeat (LTR) sequences in the DNA provirus flanking the viral genes. In the proviral DNA, the $\mathrm{R}$ region is defined as the area of terminal redundancy originally present in the RNA genome. The $5^{\prime}$ boundary of $\mathrm{R}$ is defined as the start of transcription, whereas its $3^{\prime}$ end is defined as the site of cleavage and polyadenylation. The sequences upstream of the $\mathrm{R}$ region are termed $\mathrm{U} 3$ and those downstream are termed U5. Duplication of the LTRs about the viral genome means that sequences that control transcription and 3 '-end processing are duplicated upstream and downstream of the viral genes. For the hepadnaviruses, plant caulimoviruses, and badnaviruses, a similar situation exists; however, the DNA is present in the nucleus as a circular minichromosome. Although the LTR is not duplicated at either end of the viral genes, it is effectively present at each end because of the circularization of the DNA (for review, see Rothnie et al. 1994).

Cleavage and polyadenylation of a transcript have been shown to enhance the stability, nuclear export, and translatability of the resultant mRNA (Jackson and Standart 1990; Eckner et al. 1991; Sachs 1993). The sequence elements that define the site of cleavage and polyadenylation in mammals consist of an AAUAAA element 10 25 nucleotides upstream of the cleavage site and a GUor U-rich element downstream of the cleavage site (Proudfoot 1991). In addition to this core poly|A) site, upstream sequences have also been defined for a number of poly(A) sites (Carswell and Alwine 1989; Russnak and Ganem 1990; DeZazzo et al. 1991; Russnak 1991; Valsamakis et al. 1991; Moreira et al. 1995). The biochemistry of this process is now well understood. It has been shown to involve a cleavage and polyadenylation complex that consists of several factors (Wahle and Keller 1992; Manley and Proudfoot 1994). Examples where regulation of this processing event occurs are relatively rare. However, the gene encoding the immunoglobulin $\mu$ heavy chains (secreted vs. membrane-bound; Peterson 1994), the U1A gene (Boelens et al. 1993), the adenoviral late genes (Mann et al. 1993), herpes simplex virus late 
genes (McLauchlan et al. 1992), the hepatitis $\delta$ antigen mRNA (Hsieh and Taylor 1991), and the papillomavirus late genes (Furth et al. 1994) are all thought to be regulated at this stage. Interestingly, many of these regulatory events appear to be either connected with splicing or involve splicing factors. For the immunoglobulin heavy-chain genes, a competition between splicing and polyadenylation has been suggested, whereas for the papillomaviruses, a nonfunctional upstream splice donor site inhibits the late gene poly $(A)$ site. For the UlA gene, the U1A gene product inhibits the poly(A) polymerase activity by interaction with the U1A transcript.

In the case of retroviruses and pararetroviruses, because of the duplication of the LTR regions, the poly(A) site is often present in the transcript at both the $5^{\prime}$ and the $3^{\prime}$ ends. A mechanism must therefore exist to restrict the use of the poly (A) site to downstream of the viral genes even though the sequence of the upstream poly(A) site is identical (Fig. 1). Several mechanisms have been described for different viruses. For some viruses such as Rous sarcoma virus and human T-cell leukemia virus-1, the poly $(\mathrm{A})$ site is never fully produced at the $5^{\prime}$ end (Ju and Cullen 1985; Ahmed et al. 1991). For other viruses, core poly(A) sequences are fully transcribed at the 5' end. It is possible that inefficient $\operatorname{poly}(\mathrm{A})$ site use leads to a level of readthrough at each poly(A) site passage resulting in suboptimal levels of correctly polyadenylated mRNAs. However, evidence to date suggests that this is not the case for pararetroviruses or retroviruses (Russnak and Ganem 1990; Iwasaki and Temin 1990b; Sanfaçon and Hohn 1990; Cherrington and Ganem 1992).

An attractive possibility is that RNA sequences upstream of the $\mathrm{R}$ region in $\mathrm{U} 3$, which are only ever transcribed from the downstream LTR, activate $3^{\prime}$ - end formation specifically at the $3^{\prime}$ LTR poly(A) site. Such upstream activating sequences have been described for the ground squirrel hepatitis B virus (GSHV) (Russnak and Ganem 1990; Russnak 1991), the cauliflower mosaic virus (CaMV) (Sanfaçon et al. 1991), and the spleen necrosis virus (SNV) (Dougherty and Temin 1987). Another potential explanation that the proximity of the poly(A) site in the $5^{\prime}$ LTR to the transcription start site or site of cap addition in the RNA may somehow inhibit efficient 3 '-end formation has also been suggested. The specific inhibition of promoter-proximal viral poly(A) sites has been demonstrated for GSHV (Cherrington et al. 1992), CaMV (Sanfaçon and Hohn 1990), and SNV (Iwasaki and Temin 1990a). Studies designed to establish the relative contributions of the U3 sequences and promoter proximity have suggested that promoter-proximal inhibition of $3^{\prime}$-end formation plays a more dominant role in the control of poly(A) site use than activation by upstream sequences (Iwasaki and Temin 1990a,b; Sanfaçon and Hohn 1990; Sanfaçon et al. 1991; Cherrington et al. 1992).

For the human immunodeficiency virus type 1 (HIV$1)$ the situation is more complex. The activating effect of U3 sequences has been shown using transient transfection studies (Brown et al. 1991; DeZazzo et al. 1991, 1992; Valsamakis et al. 1991), in vitro-coupled transcription and cleavage/polyadenylation systems (DeZazzo et al. 1992) and in vitro 3 '-end processing of preformed RNAs (Gilmartin et al. 1992, 1995; Valsamakis et al. 1992). In addition, it has also been suggested that proximity of the poly(A) site to the promoter plays a significant role in reducing poly(A) site efficiency at the $5^{\prime}$ end of the transcript (Weichs an der Glon et al. 1991, 1993; Cherrington and Ganem 1992; DeZazzo et al. 1992). Both of these mechanisms have been formulated using chimeric constructs in which portions of the HIV-1 LTR are fused to reporter genes. Significantly, conflicting data on the relative contributions of these two mechanisms has been found using two different systems (Cherrington and Ganem 1992; DeZazzo et al. 1992).

In an effort to reconcile this apparent controversy, we have undertaken an analysis to determine the efficiency of both the 5' LTR and 3' LTR HIV-1 poly(A) sites using full-length, infectious proviral clones. We show that although the $5^{\prime}$ LTR poly(A) site is inactive, a different poly(A) signal added at this position is efficiently utilized, resulting in stable, polyadenylated short transcripts. In the $3^{\prime}$ LTR, mutations of the previously defined U3 activating sequences reduce the efficiency of the $3^{\prime}$ LTR poly(A) site. However, this decrease is only evident in the context of competition with an efficient downstream processing signal. Surprisingly, we also demonstrate that transcription initiating from the $3^{\prime}$ LTR promoter can utilize the adjacent $3^{\prime}$ LTR poly $(A)$ site. This implies that some fundamental difference between the environment of the $3^{\prime}$ LTR and that of the $5^{\prime}$ LTR influences poly(A) site use. The 5' LTR lies immediately upstream of the major splice donor site in the viral transcript. Insertion of intron sequences downstream of the $3^{\prime}$ LTR leads to a reduced level of promoter-proximal 3' LTR poly(A) site use. In addition, specific mutation of the major splice donor site in a proviral clone leads to activation of the promoter-proximal poly(A) site at the $5^{\prime}$ LTR. These results suggest that either splice donor recognition or the process of intron splicing inhibits recognition of the HIV-1 poly(A) signals

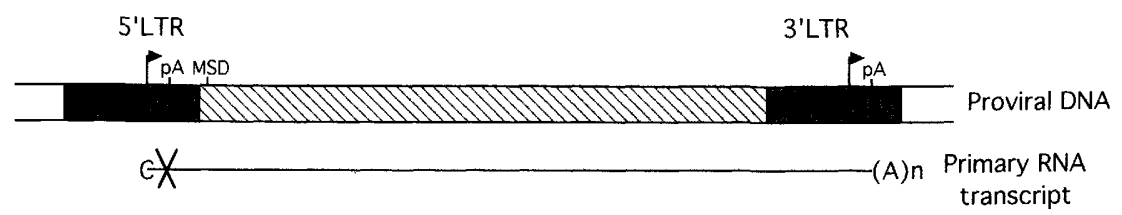

Figure 1. Poly(A) site use for HIV-1. Shown is the integrated HIV-1 provirus with the terminally redundant LTRs shaded. The cap sites, poly(A) sites, and the major splice donor site are shown. The RNA transcript is shown below this, and the $x$ denotes the readthrough of the $5^{\prime}$ LTR HIV-1 poly(A) site. 
in the $5^{\prime}$ LTR and this accounts for the selective use of the HIV-1 poly(A) site in the $3^{\prime}$ LTR but not the 5' LTR sequence.

\section{Results}

\section{Proviral clone construction and characterization}

The proviral clone used in these experiments, pNL4-3, is a combination of two HIV-1-containing genomic isolates. The upstream portion of the proviral DNA to an internal EcoRI site was provided by NY 5, and the remainder of the provirus was provided by HXB2 (Adachi et al. 1986). For pNL4-3, the two LTRs contain several mismatch mutations that should allow the $5^{\prime}$ and $3^{\prime}$ LTR-derived RNA species to be differentiated. However, this proviral clone contains $\sim 1.5 \mathrm{~kb}$ of uncharacterized genomic sequence both upstream and downstream of the HIV-1 provirus. This flanking DNA has not been sequenced and therefore introduces undesirable variation to the system. For this reason, we decided to reconstruct this proviral clone removing these flanking sequences. The resulting clone, $\mathrm{pH}$, has the NL4-3 HIV-1 provirus in pUC19 flanked by AscI sites (see Materials and methods).

To verify that the $\mathrm{pH}$ construct was capable of producing infectious virus, both $\mathrm{pH}$ and $\mathrm{pNL} 4-3$ were transiently transfected into HeLa cells and media samples were collected at various time points. After $72 \mathrm{hr}$, a coculture was set up with the T-cell line, C8166, and sampling was continued for 10 days. An assay has been developed to determine levels of viral particles by an indirect measure of the p24 protein levels (Simon et al. 1993). $\mathrm{p} 24^{\mathrm{GAG}}$ is a viral protein that forms a major part of the viral protein core that surrounds the nucleocapsid of the virus. p24 can only be detected in such a transient transfection experiment via virion production. The results of the experiment show an increase in p24 levels for both constructs that starts after $24 \mathrm{hr}$ and reaches a plateau shortly after this (Fig. 2A). The addition of C8166 cells and subsequent passage of cells caused small declines in the p24 levels, because of the necessary changes of media. However, the continuing presence of high levels of p24 protein during the coculturing of the C8166 cells shows that there was an infection cycle in the T-cell line. In addition, the kinetics of virion production and subsequent reinfection are similar for both constructs. Figure 2B shows a similar analysis for a variety of the mutants used throughout the study. These will be discussed at the relevant point in the text.

An RNase protection assay was used to allow the detection of the viral-specific RNAs from cytoplasmic RNA produced by transient transfection of the $\mathrm{pH}$ construct into HeLa cells. Figure 3A shows a riboprobe specific to the $5^{\prime}$ LTR. This is essentially identical to the $3^{\prime}$ LTR sequence except where mismatches occur (denoted by an asterisk in Fig. 3A). Figure 3B (lane 1) shows an RNase protection analysis for the $\mathrm{pH}$ construct using the 5' LTR riboprobe. Four major protected RNA species are
A
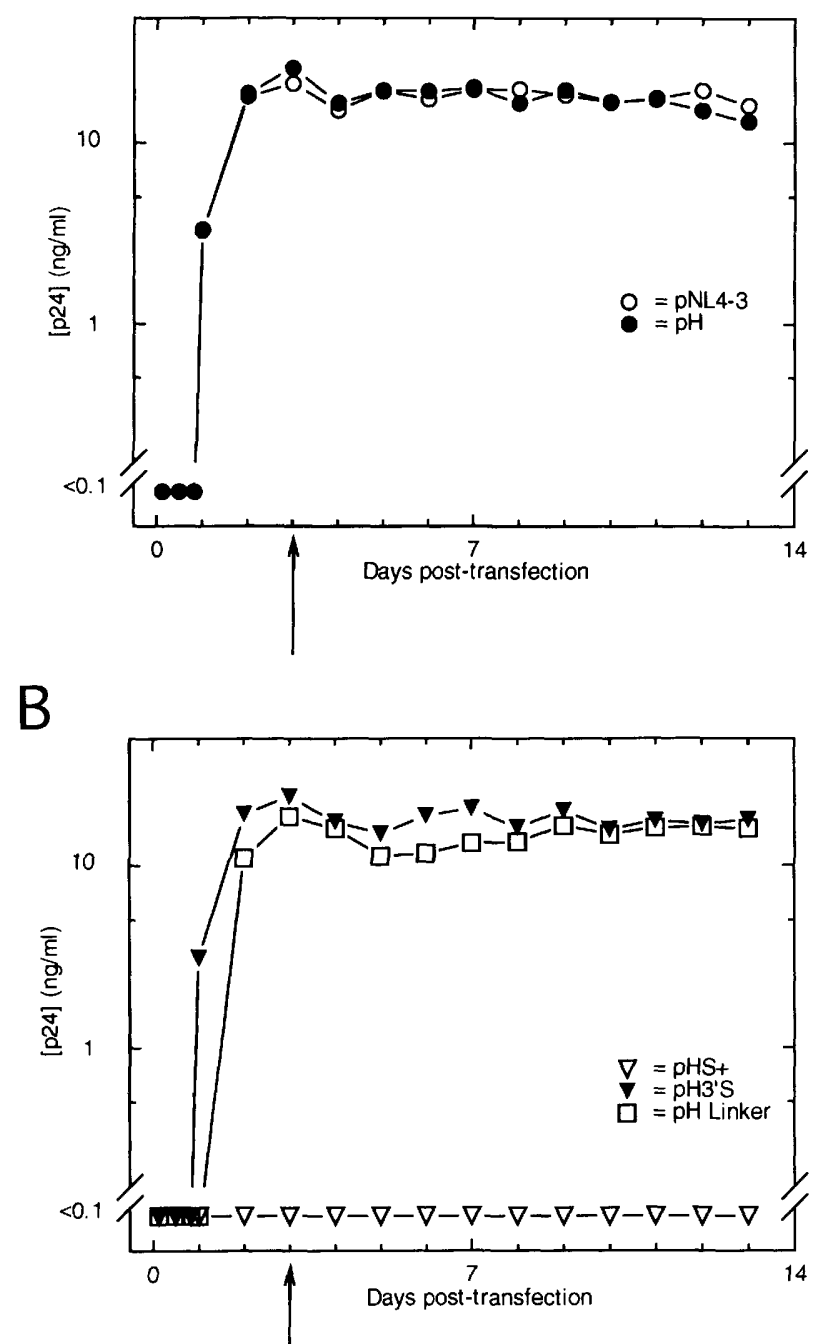

Figure 2. Characterization of $\mathrm{pH}$ and various proviral mutants. (A) A graph showing the concentration of $\mathrm{p} 24$ antigen $(\mathrm{ng} / \mathrm{ml}$ ) over the course of a HeLa cell transfection using the $\mathrm{pH}$ and pNL4-3 plasmids. The time of addition of the C8166 T-cell line is indicated by an arrow on the $x$-axis, and the concentration of p24 during the subsequent passage of this cell line is shown to day 13 post-transfection. (B) A graph showing the same analysis as for $A$, however, using a variety of the mutant constructs that are described throughout the paper.

obtained, and their identification is shown in Figure 3A. These data indicate that transcription occurs from both the $5^{\prime}$ and $3^{\prime}$ LTR promoters giving two transcripts. The first transcript contains the viral genes and is initiated at the 5' LTR cap site and polyadenylated at the $3^{\prime}$ LTR poly(A) site. The second transcript is initiated at the 3' LTR cap site and, in part, reads through vector sequences to the poly(A) site in the 5' LTR. Therefore, both viral and vector transcripts have LTR sequences at their extreme $5^{\prime}$ and $3^{\prime}$ ends and each gives two protected fragments with the LTR-specific riboprobe. 



Figure 3. The $5^{\prime}$ LTR promoter-proximal poly(A) site is not used. (A) A schematic diagram showing the $5^{\prime}$ LTR riboprobe, the pH construct, and the assignment of protected fragments for these constructs from an RNase protection analysis. For the 5' LTR riboprobe, the region of probe homology to the LTR is shown between AvaI (295) and HinfI(580), and the lines diagonal from this region represent in vitro-transcribed polylinker sequence. The regions of the LTR are shown as U3, R, and U5, with the R region hatched. The cap site, poly $(\mathrm{A})$ site, and the restriction sites $P v u I I(\mathrm{P})$ and $B g I I I(B)$, which are used for deletion in $\mathrm{pH} \Delta \mathrm{PB}$, are also shown. Sites of mismatch between the $5^{\prime}$ and $3^{\prime}$ LTRs are represented by asterisks $\left({ }^{*}\right)$. All numbering relates to the NL4-3 proviral sequence. The $\mathrm{pH}$ and $\mathrm{pH} \Delta \mathrm{PB}$ construct diagrams are shown below this. Here, the shaded rectangles represent the $5^{\prime}$ LTR and the hatched rectangles represent the $3^{\prime}$ LTR. The region deleted in the $3^{\prime}$ LTR of the $\mathrm{pH} \Delta \mathrm{PB}$-based construct is shaded. The cap and poly(A) sites are shown where necessary below the LTRs, as in the riboprobe diagram. The regions with probe homology to the HIV-1 sequence are depicted between vertical lines, and the mismatch sites are depicted by asterisks( ${ }^{*}$ ) above the LTRs. The assignment of protected species is shown below each construct. Both viral and vector transcript-derived fragments are shown. The fragments are depicted as lines below each construct with the size in nucleotides underneath. $(B)$ RNase protection analysis for the $\mathrm{pH}$ and $\mathrm{pH} \Delta \mathrm{PB}$ using the $5^{\prime}$ LTR riboprobe. Here, fragments are labeled on the basis of being derived from the $5^{\prime}$ or $3^{\prime}$ end of either the viral (Vir) or the vector (Vec) transcript. The size is also given in nucleotides, and where appropriate, specific fragments are labeled RT (readthrough) or pA [poly(A) use].

As shown in Figure 3A, transcription from the $5^{\prime}$ LTR promoter to generate the viral transcript gives a 127 nucleotide fragment protected from the cap site (453) to the end of probe homology (580) and a 226-nucleotide fragment from the $3^{\prime}$ end of the transcript generated by the mismatches (at positions 9398 and 9628 ) with the $5^{\prime}$ LTR riboprobe. This 226-nucleotide fragment actually represents RNA processed at the $3^{\prime}$ LTR poly(A) site because, as shown later, viral transcript readthrough of the $3^{\prime}$ LTR poly(A) site is not detected. The $5^{\prime}$ and $3^{\prime}$ ends of the vector transcript produced by the $3^{\prime}$ LTR promoter are mapped in a similar way (Fio. 3B, lane 1). However, these have different sizes, again owing to the differences between the $5^{\prime}$ and $3^{\prime}$ LTRs. The fragments indicate that transcription initiates in the $3^{\prime}$ LTR and in part reads through to be polyadenylated in the $5^{\prime}$ LTR. The first fragment from the cap site (9528) to the $3^{\prime}$ LTR mismatch (9624) corresponds to a 96-nucleotide RNA, and the second from the start of probe homology (295) to the cleavage site $(549)$ corresponds to the 254-nucleotide fragment. The identities of the protected RNA fragments were confirmed using the $3^{\prime}$ LTR riboprobe (Fig. 5C, 
lane 1, below) and the $5^{\prime}$ LTR SPA riboprobe (data not shown).

This analysis shows that the $\mathrm{pH}$ proviral clone transcribes viral RNA and produces infectious viral particles. In addition, transcription from the $3^{\prime}$ LTR promoter is detected. This result agrees with previous analyses using viral infections where transcription from the downstream promoter of retroviruses was reported (Cullen et al. 1984; Klaver and Berkhout 1994). However, in these previous studies, $3^{\prime}$ LTR promoter activity was significantly lower than that from the 5' LTR promoter. In the experiment above, the levels of transcription are almost identical for both of these promoters. The ratio of transcription from the $5^{\prime}$ LTR promoter to that from the $3^{\prime}$ LTR promoter was calculated as 0.98 (taking into account the radiolabel present for each fragment), although variations from 0.75 to 1.30 were seen with different transfections. These results therefore contradict the previous studies, and the possible reasons for this will be addressed later.

\section{Analysis of promoter-proximal 5' LTR poly $(A)$ site use}

A disadvantage to the NL4-3 provirus, when studying cleavage and polyadenylation directly downstream of the transcriptional initiation site, is the fact that a mismatch between the two LTRs is found at the cleavage site. Using the 5' LTR riboprobe (Fig. 3A), it is therefore impossible to distinguish transcripts that initiate on the $5^{\prime}$ LTR promoter and use the adjacent poly(A) signal from those that initiate from the 3' LTR promoter and then mismatch with the $5^{\prime}$ LTR riboprobe at the adjacent poly(A) site position. Both transcripts will generate a 96nucleotide protected product. To overcome this difficulty, we used a proviral clone, $\mathrm{pH} \Delta \mathrm{PB}$, where the $3^{\prime}$ LTR promoter is inactivated by deletion of both the transcriptional initiator element (Zenzie-Gregory et al. 1993) and the trans-activation response (TAR) sequence required for Tat-activated transcription (Feng and Holland 1988).

RNase protection mapping was performed with $\mathrm{pH} \triangle \mathrm{PB}$ using the $5^{\prime}$ LTR riboprobe (Fig. 3B, lane 2). Figure $3 \mathrm{~A}$ shows the identification of the protected fragments using this probe and indicates that they all derive from the viral transcript. As shown in Figure 3B (lane 2), the $3^{\prime}$ end of the viral transcript protects two fragments, 112 and 76 nucleotides, as a result of the $3^{\prime}$ LTR deletion (Fig. 3A). The $5^{\prime}$ end of the viral transcript is represented by the 127-nucleotide fragment. The presence of the 127nucleotide fragment and the absence of a 96-nucleotide fragment in lane 2 demonstrate that viral transcripts are not processed at the poly(A) site directly downstream of 5' LTR promoter.

We conclude that the $\triangle \mathrm{PB}$ deletion inactivates transcription from the $3^{\prime}$ LTR, so that we can now discriminate between processing and readthrough at the $5^{\prime}$ LTR poly(A) site. We therefore show that use of the $5^{\prime}$ LTR HIV-1 poly(A) site is below detectable limits (by RNase protection): Less than $1 \%$ of the readthrough species is detected. This is in agreement with a previous study
(Cherrington and Ganem 1992) in which poly(A) site usage in the $5^{\prime}$ LTR of the HIV-1 provirus was undetectable.

\section{$A$ heterologous poly $(A)$ site is efficiently used in the $5^{\prime} L T R$}

The results above suggest that the promoter-proximal poly(A) site in the $5^{\prime}$ LTR is inactive. However, it is also possible that this $\operatorname{poly}(\mathrm{A})$ is active and that the short transcripts produced are unstable in the cytoplasm or inefficiently transported to the nucleus. These latter two possibilities have been postulated by a number of groups to explain results in which efficient polyadenylation is not detected proximal to a promoter, even though the levels of readthrough polyadenylated RNAs decrease (Weichs an der Glon et al. 1991; Cherrington et al. 1992). To analyze the promoter-proximal poly(A) site use using a heterologous poly(A) site, the efficient synthetic poly(A) site (SPA) (Levitt et al. 1989) was used to directly replace the 5' LTR poly(A) site. This 5' LTR SPA derivative was used in the context of both $\mathrm{pH}$ and $\mathrm{pH} \triangle \mathrm{PB}$, giving the proviral clones $\mathrm{pH} 5^{\prime} \mathrm{S}$ and $\mathrm{pH} 5^{\prime} \mathrm{S} \triangle \mathrm{PB}$, respectively.

These clones were transiently transfected, and cytoplasmic RNA was purified as before. RNA mapping experiments were performed using a $5^{\prime}$ LTR SPA riboprobe as shown in Figure 4A. The RNase protection using this riboprobe is shown in Figure 4B. On the basis of this experiment as well as through the use of the $5^{\prime}$ and $3^{\prime}$ LTR riboprobes (data not shown), it was possible to establish the identity of the RNA species produced from these constructs (Fig. 4A). As with the $\mathrm{pH}$ construct, transcription of $\mathrm{pH} 5^{\prime} \mathrm{S}$ is directed by both the $5^{\prime}$ and $3^{\prime}$ LTR promoters, generating viral- and vector-based transcripts. The 68-nucleotide and 57-nucleotide fragments should represent the $5^{\prime}$ end and the 247-nucleotide fragment the 3' end of the $3^{\prime}$ LTR-initiated vector transcripts (Fig. 4A). As shown in Figure 4B (lane 1), a strong 68nucleotide and fainter 247 -nucleotide band is present but absent in lane 2 (which shows the $\triangle P B$ derivative) confirming that these bands derive from $3^{\prime}$ LTR transcription. However, little of the 57-nucleotide RNA fragment is detectable. Because both the 68- and 57-nucleotide protected fragments will result from $3^{\prime}$ LTR promoter activity and their respective regions of homology lie $<60$ nucleotides apart, either side of the $3^{\prime}$ LTR poly(A) site, they would be expected to give almost equal intensity bands. However, as shown later, the $3^{\prime}$ LTR poly(A) site directly downstream of the $3^{\prime}$ LTR promoter is efficiently used, reducing the level of readthrough transcription. Therefore, the amounts of both the 57- and 247nucleotide fragments would be expected to be much weaker than that of the 68-nucleotide fragment.

The 89-, 189-, and 198-nucleotide fragments derive from the 5' LTR-directed viral transcription. The 89-nucleotide species corresponds to a transcript that starts at the 5' LTR cap site and is subsequently processed at SPA directly downstream (Fig. 4A). The multiple bands above the 89-nucleotide band are caused by incomplete RNase 



Figure 4. A heterologous poly(A) site is used in the promoter-proximal position for the $5^{\prime}$ LTR. (A) A diagram showing the $5^{\prime}$ LTR SPA riboprobe used for RNase protection analysis. The diagram is the same as for the $5^{\prime}$ LTR riboprobe (Fig. 3A), except the region of SPA inserted is shown as a rectangle where shaded regions represent short polylinker sequences. The size of the insert and distance from the $5^{\prime}$ end of the insert to the cleavage site are shown below. In addition, the area of probe homology is extended to downstream of the 5' LTR to the Narl site (640); this is shown as a shaded rectangle. The sites of cap formation, polyadenylation, and the end of $\mathrm{U} 5$ are also given. The $\mathrm{pH} 5^{\prime} \mathrm{S}$ and $\mathrm{pH} 5^{\prime} \mathrm{S} \triangle \mathrm{PB}$ construct diagrams and the identity of protected fragments using the $5^{\prime}$ LTR SPA riboprobe are shown below this. The diagram is arranged as in Fig. 3A, except the fragments representing SPA use and readthrough are specifically labeled. $(B)$ RNase protection analysis for the $\mathrm{pH} 5$ 'S and $\mathrm{pH} 5^{\prime} \mathrm{S} \Delta \mathrm{PB}$ using the 5' LTR SPA riboprobe. Protected fragments are depicted as in Fig. 3B, except those deriving from the pH5'S construct are on the left of the photograph and those from the pH5'S $\triangle \mathrm{PB}$ construct are on the right. The allocations are as in $A$. Fragments representing SPA use and readthrough are specifically labeled.

digestion. Both the 189- and 198-nucleotide fragments derive from readthrough of the SPA site leading to viral transcription. The 189-nucleotide fragment represents the $5^{\prime}$ end, and the 198-nucleotide fragment represents the $3^{\prime}$ end of this viral transcript (Fig. 4A).

Figure $4 \mathrm{~B}$, lane 2, shows the protection pattern for $\mathrm{pH} 5^{\prime} \mathrm{S} \triangle \mathrm{PB}$. As stated previously, the $\triangle \mathrm{PB}$ deletion abolishes vector transcription from the $3^{\prime}$ LTR promoter. Similarly to lane 1, the 89-nucletide fragment represents SPA use directly downstream of the 5' LTR promoter. Readthrough of SPA generating the viral transcript gives the 189-nucletide fragment at the $5^{\prime}$ end. Readthrough to the $3^{\prime}$ LTR should give a 112- and a 48-nucleotide fragment as a result of $\triangle \mathrm{PB}$ deletion (Fig. $4 \mathrm{~A}$ ). However, pro- cessing at the SPA proximal to the 5' LTR promoter must lead to a decrease in the levels of $3^{\prime}$ LTR readthrough species. This means that in lane 2 , only the larger nucleotide 112 is visible as a faint band. The identity of this band as separate from one of the partial digestion products for the 89-nucleotide fragment is verified by its absence from lane 1, where a nonmutated 3' LTR is present. The 48-nucleotide fragment is undetectable but may be present at a similar level to the 112 nucleotide fragment after the radioactive bases in the probe fragments are accounted for, as both originate from the same RNA species.

This experiment demonstrates that when the HIV-1 poly(A) site is directly replaced with SPA in the 5' LTR, 
then efficient processing at this site is detectable using a homologous riboprobe. The level of polyadenylation at SPA (89-nucleotide fragment) when expressed as a percentage of the total 5' LTR transcription (89- + 189-nucleotide fragments) is $84.6 \%$ for the $\mathrm{pH}$-based construct and $86 \%$ for the $\triangle P B$-based construct. In addition, the ratio of transcripts initiating at the $5^{\prime}$ LTR promoter to those initiating at the $3^{\prime}$ LTR promoter is less than for $\mathrm{pH}$ (Fig. 5D). The fact that placing a poly(A) site between two promoters enhances use of the downstream promoter and inhibits use of the upstream promoter on a circular plasmid has been described previously (Eggermont and Proudfoot 1993).

\section{Polyadenylation at $\sim 250$ nucleotides from the promoter}

We demonstrate above that cleavage and polyadenylation can occur efficiently directly downstream of the transcriptional initiation site using a heterologous poly(A) site in the proviral 5' LTR and for the HIV-1 poly(A) site at the $3^{\prime}$ LTR. We therefore decided to analyze poly(A) site use farther downstream. Previous studies have demonstrated that the HIV-1 poly(A) site is read through at a distance of 450 nucleotides from the cap site (Weichs an der Glon et al. 1991, 1993). Poly(A) sites were therefore inserted into the proviral clone at the BssHII site, upstream of the major splice donor site. The poly(A) sites used were the HIV-1 poly(A) site (BgllI to HinfI) to give $\mathrm{pHH}+$ and the SPA inserted in both orientations to give $\mathrm{pHS}+$ and $\mathrm{pHS}-$ (Fig. 5A). These proviral subclones were made in both $\mathrm{pH}$ and $\mathrm{pH} \Delta \mathrm{PB}$ that lacks $3^{\prime}$ LTR promoter activity.

The same analysis was performed as before, although for the $\triangle \mathrm{PB} 3^{\prime}$ LTR constructs, a 3' LTR riboprobe was used instead of the $5^{\prime}$ LTR riboprobe. The protected fragments obtained for the pH subclones using the $5^{\prime}$ LTR riboprobe are shown in Figure $5 \mathrm{~B}$, lanes $1-5$, and are identical to those seen in Figure 3B, lane 1. The identification of RNA species is the same as for $\mathrm{pH}$ shown in Figure $3 \mathrm{~A}$. This is because the site of insertion of the poly(A) sites lies outside the probed region.

Therefore, the 127- and 226-nucleotide RNA fragments derive from transcription from the $5^{\prime}$ LTR promoter and denote the $5^{\prime}$ and $3^{\prime}$ ends of the viral transcripts, respectively. The $5^{\prime}$ (127-nucletide) to $3^{\prime}$ (226nucleotide) ratio relative to that for the $\mathrm{pH}$ construct gives an estimation of the extent of inserted poly(A) site use. From this it can be seen that the addition of the HIV-1 poly(A) site $(\mathrm{pHH}+)$ and SPA in the negative orientation (pHS -) had little effect on the ratio of these two fragments (Fig. 5B, cf. lanes 4 and 5 with lane 1). However, slight decreases were noted on quantitation (Fig. 5E) that suggest that both the HIV-1 poly(A) site and the inverted SPA (which contains an AAUAAA element) give a small amount of 3 '-end formation. The insertion of SPA in the positive orientation abolished all steadystate RNA species (lane 3). This was not attributable to a poor transfection as the cotransfection control for this experiment is higher than the others. In addition, Figure
2A shows that this proviral mutant gives no $\mathrm{p} 24$ protein and therefore produces no virion particles. The cotransfection of a Tat-producing plasmid with this construct restored the steady-state RNA species (lane 2); however, the 226-nucleotide fragment denoting readthrough to the 3 ' LTR was undetectable, suggesting $100 \%$ SPA use. For all of these poly(A) site insertions, the ratio of transcription from the two LTR promoters decreases to a variable degree (Fig. 5D); that is, for $\mathrm{pHS}++$ Tat, transcription from the $3^{\prime}$ LTR promoter (denoted by the 96-nucleotide fragment is now severalfold higher than that from the $5^{\prime}$ LTR promoter (denoted by the 127-nucleotide species). In a number of cases, poly(A) site insertion has been shown to relieve transcriptional interference, presumably by encouraging termination prior to the downstream promoter (Cullen et al. 1984; Eggermont and Proudfoot 1993). If each of these poly(A) sites were used to a variable degree, a variation in the relief of interference may be seen.

The results obtained for the $\Delta \mathrm{PB}$ derivatives are shown in Figure $5 \mathrm{C}$, and maps of the protected fragments are shown in Figure 6C, below. Here, the 96-nucleotide fragment denotes the $5^{\prime}$ end and the 140-/78-nucleotide fragments denote the $3^{\prime}$ end of the viral transcript. As before, $\mathrm{pHH}+$ and $\mathrm{pHS}-$ show little difference to the $\mathrm{pH}$ lane (cf. lanes 4 and 5 with lane 1), suggesting inefficient $3^{\prime}$ end formation at the inserted poly(A) site. The ratio of $5^{\prime}$ LTR promoter to 3' LTR poly(A) species is similar to those from the $\mathrm{pH}$ constructs (data not shown). Once again, pHS + gives no steady-state RNA in the absence of Tat and in its presence only the $5^{\prime}$ end of the transcript can be detected. In addition, no significant difference is seen in the levels of transcription from the $5^{\prime}$ LTR promoter between the different constructs.

The results obtained for both the $\mathrm{pH}$ and $\mathrm{pH} \Delta \mathrm{PB}$ experiments suggest that the SPA is used $100 \%$, whereas the HIV-1 poly(A) site or SPA in the reverse orientation is used to a lesser degree. The SPA use is designated $100 \%$ for several reasons. First, no readthrough to the $3^{\prime}$ LTR HIV-1 poly(A) site was detected. Second, to detect steady-state RNAs it was necessary to add the Tat transactivator. The complete absence of steady-state RNA in the absence of exogenous Tat indicates that the SPA must be used exclusively and so prevents production of endogenous Tat mRNA that leads to a positive feedback loop. These results also have bearing on the theory of transcriptional interference. The results show that the HIV-1 poly(A) site and SPA in the reverse orientation are used to a small extent (Fig. 5E). Furthermore, the changes in the ratio of $5^{\prime} \rightarrow 3^{\prime}$ LTR promoter activity for these clones (Fig. 5D) correlate well with the extent of inserted poly|A) site use. This is consistent with the use of the inserted poly(A) site and subsequent termination causing a partial relief of transcriptional interference, in agreement with previous results (Eggermont and Proudfoot 1993|.

Mutation of upstream sequences in the $3^{\prime}$ LTR

Many studies have analyzed the effects of upstream se- 


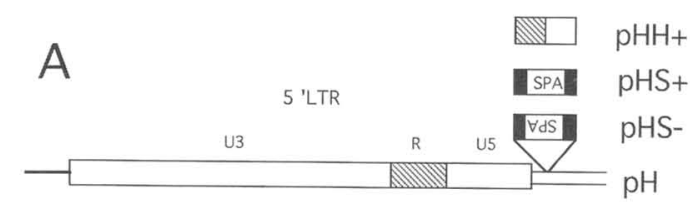

B



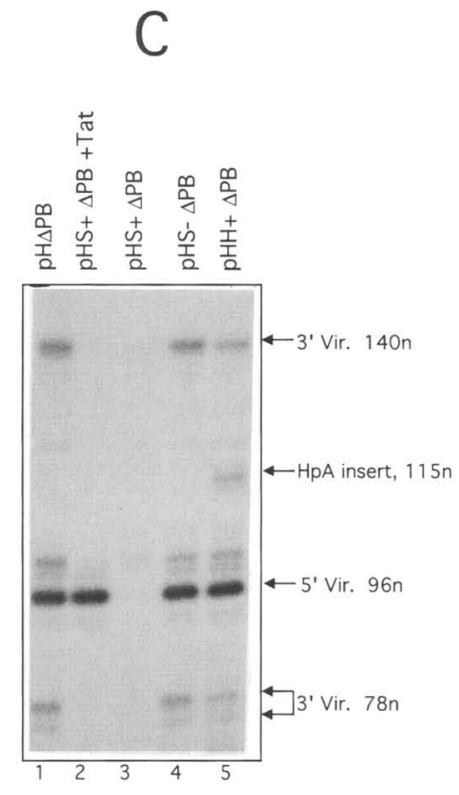

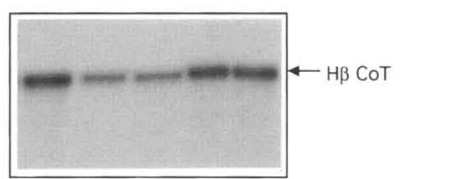

D

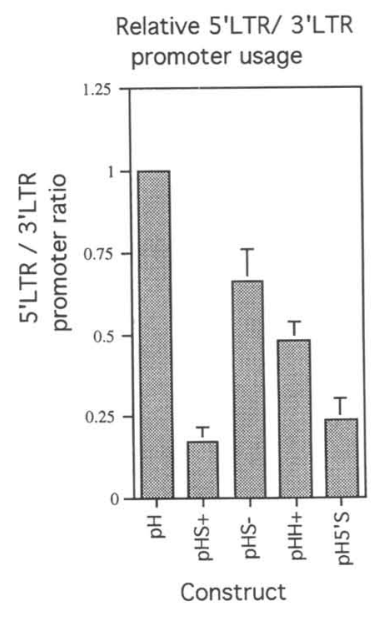

E

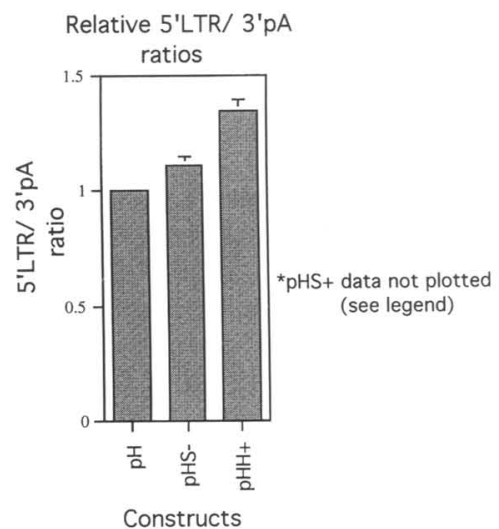

Figure 5. Analysis of poly $(A)$ sites $\sim 250$ nucleotides from the promoter. $(A)$ A diagram showing the $5^{\prime}$ LTR and the downstream BssHII site used for poly(A) site insertion. The hatched region in the LTR and the HIV-1 poly(A) site represents the R region. Downstream of the LTR, the open rectangle represents viral, and the line upstream of the LTR represents vector, sequences. The resultant constructs $\mathrm{pH}, \mathrm{pHS}+, \mathrm{pHS}-$, and $\mathrm{pHH}+$ are depicted at right. $(B)$ RNase protection analysis for the $\mathrm{pH}, \mathrm{pHS}+$, $\mathrm{pHS}-$, and $\mathrm{pHH}+$ constructs using the $5^{\prime}$ LTR riboprobe. The construct names are shown at the top, and the cotransfection of a Tat-producing plasmid (pOGS213) for the pHS + clone is shown with the construct name. The protected fragments are shown at right. These are as in Fig. 3A. Beneath this, an S1 cotransfection control using a human $\beta$-globin end-labeled EcoRI DNA probe is depicted. $(C)$ As for $B$, except that RNA from the $\triangle \mathrm{PB}$ constructs was analyzed and the 3' LTR riboprobe was used for the RNase protection analysis. This probe and the RNA products obtained are described in Fig. $6 \mathrm{C}$. The extra band in the pHH + lane is attributable to the inserted HIV-1 poly(A) site and shows readthrough of this poly(A) site. (D) A graph shows the ratio of $5^{\prime}$ LTR promoter use to $3^{\prime}$ LTR promoter use for $\mathrm{pHS}+, \mathrm{pHH}+$, and $\mathrm{pH} 5$ 'S relative to this same ratio for the $\mathrm{pH}$ clone that is arbitrarily set at 1 . The positive error bars represent the standard deviations from a minimum of two independent experiments. $(E)$ A graph shows the ratio between the fragment that represents the $5^{\prime}$ end of the viral transcript (127-nucleotide band on $\left.B\right)$ and that representing the $3^{\prime}$ end of the viral transcript (226-nucleotide band on $B$ ) for the $\mathrm{pHS}-$ and $\mathrm{pHH}+$ constructs relative to the $\mathrm{pH}$ construct where the ratio has been arbitrarily set at 1 . This same ratio for the pHS + construct cannot be calculated even in the presence of exogenous Tat as the $3^{\prime}$ end of the transcript is undetectable, i.e. there is $100 \%$ use of SPA. The positive error bars represent standard deviations between three independent experiments.

quences in the HIV-1 transcript on the use of the $3^{\prime}$ LTR poly $(A)$ site. Precise mutations that lead to decreased HIV-1 poly(A) site efficiency have been described in both cell culture assays and in vitro $3^{\prime}$-end processing reactions (Valsamakis et al. 1991, 1992). A major upstream region from position 9507 to 9543 , and a minor upstream region from position 9453 to 9471 in the NL4-3 provirus has been defined (Fig. 6B) (Valsamakis et al. 1991). It has been shown recently that the major $\mathrm{U} 3$ sequences increase the efficiency of AAUAAA recognition by the 
Ashe et al.

A



B

$\mathrm{pH}$

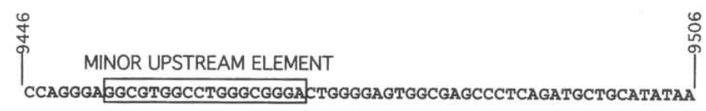

pHDU3 AATGCTGCTTGTGCCTGGCTAGAAGCACAAGAGGAGGAAGAGTGGGTPTTCCAGTCACA

MINOR UPSTREAM -

pH $\triangle$ PB ATCGAGCTTGCTACAAGGGACTTTCCGCTGGGGACTTTCCAGGGA GGCGTGGCCTGGGCG

pHLinker CCAGGGA GGCGTGGCCTGGGCGGAACTGGGGAGTGGCGAGCCCTCAGATGCTGCATATAA

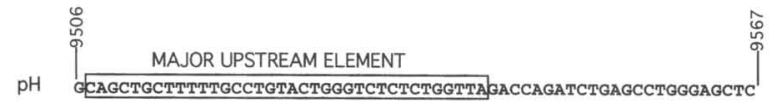

PHAU3 CCTCAGGTACCTITCCACCAATGACTTACAAGGCAGCTGTAGATCTGAGCCTGGGAGTC ELEMENT

PHAPB FGA ATGGGGAGTGGCGAGCCTCAGATGCTGCATATAAGCAGGATCTGAGCCTGGGAGCTC

pHLinker GCAGGACGAAAAACGGACATGACCCAGAGAGACCAATGACCAGATCTGAGCCTGGGAGCTC
3'LTR riboprobe

$\mathrm{pH}$
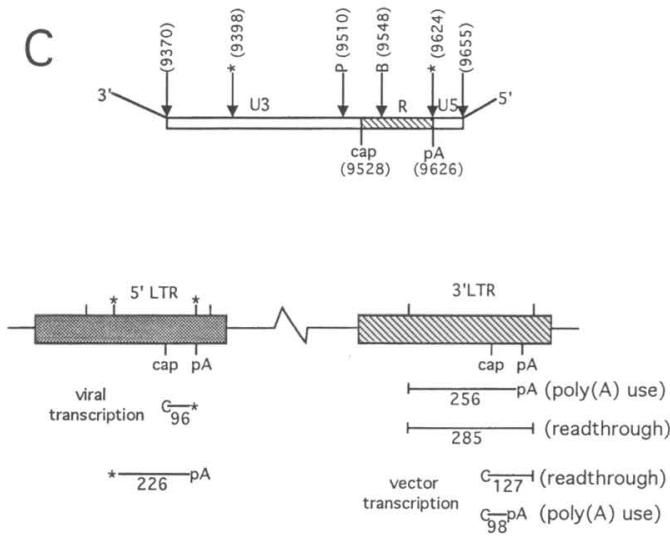

$\mathrm{pH} \Delta \mathrm{U} 3$

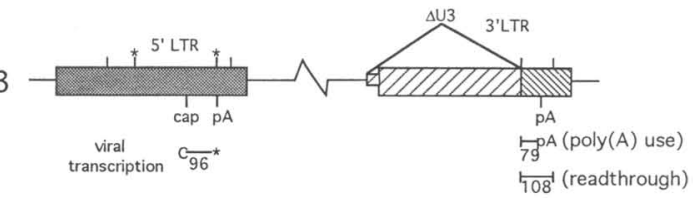

$\mathrm{pH} \triangle \mathrm{PB}$
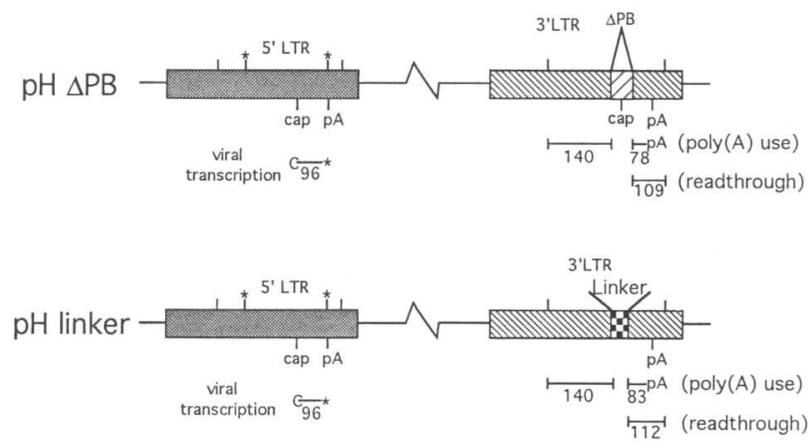

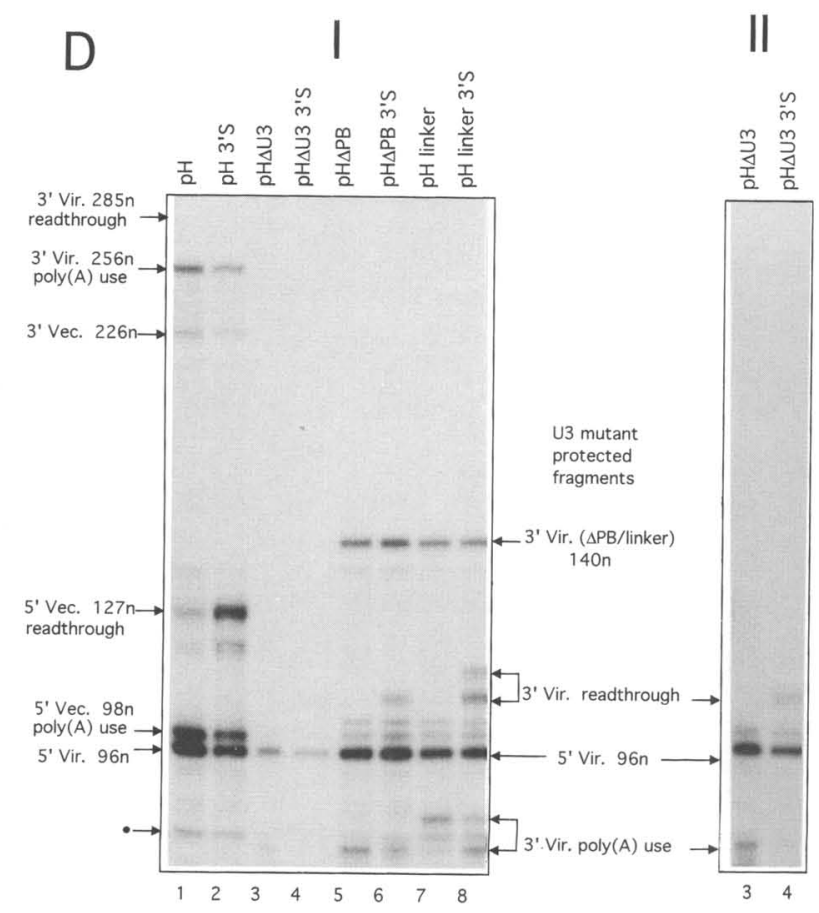

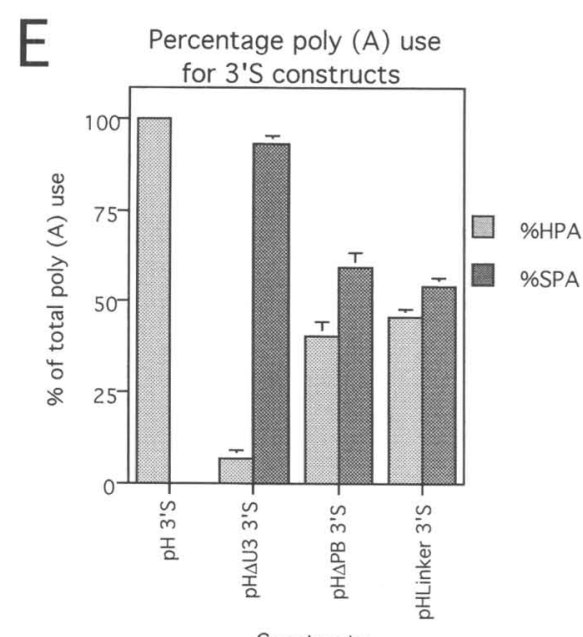

Constructs

Figure 6. (See facing page for legend.) 
cleavage and polyadenylation specificity factor $(\mathrm{CPSF})$ in a reconstituted cleavage assay and require the formation of TAR to juxtapose them to the core poly(A) site (Gilmartin et al. 1992, 1995). In addition, it has been speculated that a region rich in pyrimidines is the active area of the upstream sequence (Gilmartin et al. 1995).

We have analyzed the effect of deletion or mutation of these sequences on the efficiency of 3 '-end formation in the proviral clone. U3 mutations were constructed that delete the entire $\mathrm{U} 3$ region $(\mathrm{pH} \Delta \mathrm{U} 3)$ and a more specific region containing the major upstream element ( $\mathrm{pH} \Delta \mathrm{PB})$. In addition, a substitution mutation was made where a linker replaces the major upstream element ( $\mathrm{pH}$ linker). The 3' LTR region of these proviral constructs is shown in Figure 6A, and the exact sequence of the relevant region upstream of the core poly(A) site is shown in Figure $6 \mathrm{~B}$ with homologies to the $\mathrm{pH}$ sequence shown in boldface type.

Figure 6D, lane 1, shows five protected fragments obtained using a $3^{\prime}$ LTR riboprobe with the $\mathrm{pH}$ construct. As shown in Figure 6C, the 96- and 256-nucleotide protected fragments map the $5^{\prime}$ and $3^{\prime}$ end of the viral transcript and the 127- and 226-nucleotide fragments map the ends of the vector transcript. No $3^{\prime}$ LTR poly(A) site readthrough bands are detectable (285 nucleotides), therefore, the HIV-1 poly $(\mathrm{A})$ site is used exclusively for viral transcription. The level of transcription from the 3' LTR promoter (Fig. 6D, lane 1, the 127-nucleotide fragment) does not correlate well with the level seen in the $5^{\prime}$ LTR riboprobe experiment (Fig. 3B, lane 1, 5' Vec, 96 nucleotides). We therefore reasoned that the protected species slightly above the 96-nucleotide fragment (labeled 98n in Fig. 6D, lane 1) also derives from the $3^{\prime}$ LTR promoter. This suspicion was further validated below, when in the absence of $3^{\prime}$ LTR transcription this fragment is reduced in intensity (lanes $3,5,7)$. The precise identity of this transcript will be discussed later. The efficient utilization of the promoter-distal $3^{\prime}$ LTR
poly(A) site observed here is in agreement with a number of other studies (DeZazzo et al. 1991; Valsamakis et al. 1991; Weichs an der Glon et al. 1991; Cherrington and Ganem 1992).

The protected fragments using the 3 ' LTR riboprobe with the pHAU3 proviral clone are 96 and 79 nucleotides, [Fig. 6D, lane 3 (panels I and II)] and represent the $5^{\prime}$ and $3^{\prime}$ ends of the viral transcript, respectively (Fig. $6 \mathrm{Cl}$. The $\Delta \mathrm{U} 3$ deletion removes all the promoter elements in the $3^{\prime}$ LTR and disrupts the TAR RNA secondary structure. Therefore, transcription from the $3^{\prime}$ LTR promoter is inactive. The level of steady-state RNA detected here was consistently five- to sixfold lower than that from $\mathrm{pH}$. The reason for this is unclear and may either be attributable to a direct effect on transcription levels or an effect on nuclear export or cytoplasmic stability of the RNA. Readthrough at the $3^{\prime}$ LTR poly(A) site would produce a protected fragment of 108 nucleotides (from the site of deletion, 9548, to the end of probe homology, 9655). In addition, readthrough of the $3^{\prime}$ LTR poly(A) site would lead to use of the $5^{\prime}$ LTR HIV-1 poly(A) site around the plasmid, giving a 226-nucleotide fragment. On longer exposure of the gel, neither of these fragments were detected (panel II).

The second of the two deletion clones, $\mathrm{pH} \Delta \mathrm{PB}$ (Fig. $5 \mathrm{~A})$, removes the major sequence element, described previously (Valsamakis et al. 1991). Figure 6D (lane 5) shows the RNase protection analysis using a 3' LTR riboprobe. A 96-nucleotide fragment maps the $5^{\prime}$ end of this viral transcript, as for $\mathrm{pH}$. At the $3^{\prime}$ end, the $\triangle \mathrm{PB}$ deletion results in two protected fragments of 140 nucleotides and 78 nucleotides as shown in Figure 6C. Readthrough of the $3^{\prime}$ LTR poly(A) site of this clone would give an expected protected species of 107 nucleotides from the deletion site (9548) through to the end of probe homology (9655) and would also give the 5' LTR 226-nucleotide species. Neither of these fragments is detectable in Figure $6 \mathrm{C}$, lane 5 . The level of steady-state RNAs using this

Figure 6. Upstream sequences increase the efficiency of the 3' LTR poly(A) site, but only in competition with efficient downstream processing signals. (A) A diagram showing the $3^{\prime}$ LTR of the $\mathrm{pH}$ construct with a variety of mutations. Deletion between the two $B g I I I$ $(\mathrm{Bg})$ sites gives the $\mathrm{pH} \Delta \mathrm{U} 3$ construct, deletion between a $P$ vuII $(\mathrm{Pv})$ and $\mathrm{Bg}$ gives $\mathrm{pH} \Delta \mathrm{PB}$, and insertion of a linker sequence (checkered rectangle/ between Pv and Bg gives pH linker. For each of these constructs, the site of insertion of SPA downstream of the $3^{\prime}$ LTR is also shown, giving the $3^{\prime}$ S derivatives. $(B)$ A sequence comparison for the region upstream of the core poly $|A|$ site for each of the mutants described. For the pH clone, a region between 9446 and 9567 in the $3^{\prime}$ LTR, 59 nucleotides upstream of the cleavage site, is shown, and previously identified activatory sequences are boxed. The equivalent region for each of the U3 mutant constructs is shown below, and regions homologous to the activatory sequences are underlined. In addition, where the activatory sequences are still present they are boxed as before. Identical sequences to wild type for the U3 mutants are represented in boldface type. $(C)$ A diagram showing the 3' LTR riboprobe and the identification of protected fragments for the $\mathrm{pH}, \mathrm{pH} \Delta \mathrm{U} 3, \mathrm{pH} \Delta \mathrm{PB}$, and $\mathrm{pH}$ linker constructs, using the $3^{\prime}$ LTR riboprobe. The layout and labeling for this diagram are similar to that for Fig. 3A. However, the site of linker insertion for $\mathrm{pH}$

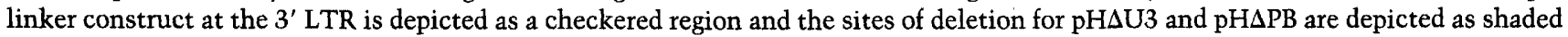
regions. $(D) I$ and $I I$ show a RNase protection for the constructs described above using the $3^{\prime}$ LTR riboprobe. II is a longer exposure of lanes 3 and 4 of $I$. The construct names are shown at the top and protected fragments at the sides of the photographs. Those fragments for the $\mathrm{pH} / \mathrm{pH} 3$ 'S constructs are shown at left of $I$. The expected fragments for the U3 mutants are shown between $I$ and II. The identity of all fragments from these constructs is shown in C. Fragments representing 3' LTR poly(A) site use or readthrough are specifically labeled. The band labeled probably represents an overdigestion product deriving from all the protected fragments because it is present in all of the lanes and its intensity changes relative to the intensity of other fragments. $(E)$ A graph showing the percentage use of the HIV-1 and the percentage use of SPA for each of the 3'SPA-based constructs. The positive error bars represent the standard deviation between at least two experiments. 
clone is similar to that from $\mathrm{pH}$ when cotransfections are considered (data not shown).

The final mutation replaces the major sequence element with a linker (Fig. 6A,B). Here, the protected fragments are identical to those for $\mathrm{pH} \Delta \mathrm{PB}$ except the size of the 78-nucleotide fragment should be increased to 83 nucleotides because of a more extensive homology between probe and RNA near the BgIII site (Fig. 6B,D). However, as shown in Figure 6C, lane 7, the 83-nucleotide fragment appears as a doublet, suggesting a degree of overdigestion near the BglII site. Readthrough would give a fragment of 112 nucleotides and may generate a 226-nucleotide fragment from the 5' LTR. However, neither of these species was detected. In addition, when this construct was used to measure p24 levels, very little difference to the level seen for the $\mathrm{pH}$ construct was detected, suggesting that the mutation does not affect the production of and subsequent infection by progeny virions (Fig. 2B).

Therefore, all three U3 mutations appear to have little effect on the degree of readthrough at the HIV-1 poly(A) site. However, an analysis of the sequences present upstream of the core poly $(\mathrm{A})$ site for $\Delta \mathrm{U} 3$ reveals a pyrimidine-rich region at an analogous position to that in the $\mathrm{pH}$ proviral clone and a sequence analogous to the minor upstream element (underlined in Fig. 6B). In addition, both the $\mathrm{pH} \triangle \mathrm{PB}$ and $\mathrm{pHlinker}$ mutations still contain the minor upstream activatory element, and for the $\mathrm{pH} \triangle \mathrm{PB}$ mutation, in particular, this is brought closer to the core poly(A) site. An in vitro study has found that the juxtapositioning of upstream elements to the core poly(A) site via the TAR RNA secondary structure increases the upstream elements activatory effect /Gilmartin et al. 1992). However, computer predictions show no stable RNA secondary structure between the possible upstream sequences and the core poly(A) site for $\mathrm{pH} \Delta \mathrm{U} 3$ or the minor upstream elements and the core poly $(\mathrm{A})$ site for $\mathrm{pH} \triangle \mathrm{PB}$ and $\mathrm{pHlinker}$ such as TAR found in $\mathrm{pH}$ (data not shown). We would predict on the basis of previous experiments that each of these mutations would significantly reduce HIV-1 poly(A) site use, and this is not the case.

\section{Effects of the 3' LTR U3 mutations in competition with an efficient poly $(A)$ site}

The constructs above tested the efficiency of the $3^{\prime}$ LTR poly(A) site where the only competition was the $5^{\prime}$ LTR poly(A) site positioned $\sim 3 \mathrm{~kb}$ downstream. We decided to increase the level of competition for $\mathrm{pH}$ and each of the U3 mutant constructs by introducing an efficient processing signal, SPA, $\sim 100$ nucleotides downstream of the HIV-1 3' LTR poly(A) sequence. These constructs are shown in Figure 6A and are termed pH 3'S, pHAU3 3'S, $\mathrm{pH} \triangle \mathrm{PB} 3^{\prime} \mathrm{S}$, and $\mathrm{pH}$ linker 3'S.

The protection pattern for these constructs using the 3' LTR riboprobe remains the same, because SPA is inserted outside the area of probe homology. For the $\mathrm{pH}$ construct, there is no detectable 285-nucleotide fragment that would denote readthrough of the $3^{\prime}$ LTR
poly(A) signal by viral transcription (Fig. 6C, lane 21. Therefore, use of the HIV-1 poly(A) site is efficient, allowing no readthrough to the downstream SPA. In addition, Figure $2 \mathrm{~B}$ shows that $\mathrm{p} 24$ levels for this construct are similar to those from the $\mathrm{pH}$ construct. For each of the U3 mutations, a readthrough fragment was noted on addition of SPA (Fig. 6C, lanes 4,6,8). The expected sizes of readthrough fragments for $\mathrm{pH} \Delta \mathrm{U} 3, \mathrm{pH} \Delta \mathrm{PB}$, and $\mathrm{pH}$ linker are 108, 107, and 112 nucleotides, respectively. As stated previously, $\mathrm{pH}$ linker $3^{\prime} \mathrm{S}$ generates a doublet that is assumed to arise from overdigestion. The fact that both the fragment denoting polyadenylation at the $3^{\prime}$ LTR HIV-1 poly(A) site and that denoting readthrough produce this doublet pattern suggests that there is an RNase-sensitive region upstream of the predicted end of probe homology at the $5^{\prime}$ end of the protected fragment. The ratio of $5^{\prime}$ LTR to total $3^{\prime}$-end formation for these experiments does not change compared with the situation in the absence of strong downstream competition (data not shown). However, mutation of U3 sequences causes a percentage of the transcripts to readthrough presumably because of SPA use. On quantitation, the level of poly $(\mathrm{A})$ site readthrough correlates well with the severity of the mutation, as determined by the amount of sequence mutated and the level of reformation of upstream sequences for each mutant (Fig. 6E).

\section{Polyadenylation directly downstream of the $3^{\prime}$ LTR promoter}

The careful mapping of RNA products obtained by RNase protection analysis of the various proviral clones described in these studies has pointed consistently to the surprising fact that the $3^{\prime}$ LTR poly(A) site efficiently cleaves and polyadenylates $3^{\prime}$ LTR-initiated vector transcription. Thus, we show in Figure 6D the existence of a 98-nucleotide fragment with a 3' LTR riboprobe and that this fragment is diminished when the 3' LTR promoter is inactivated. In addition, the analysis for the $\mathrm{pH} 5$ 'S construct (Fig. 4B) shows that transcripts from the $3^{\prime}$ LTR are high before the poly(A) site (68-nucleotide fragment) but low after it (57-nucleotide fragment). RNA mapping of pH5'S transcripts using a 3' LTR riboprobe also allowed the detection of the 98-nucleotide fragment (seen in Fig. 6C) in the absence of the 5' LTR promoter 96nucleotide fragment, as the $5^{\prime}$ LTR transcripts mismatch at the site of SPA insertion to give a much smaller fragment (data not shown). It is also evident from Figures 3, 5 , and 6 that the yield of $3^{\prime}$ ends for the two LTR transcripts is significantly lower than $5^{\prime}$ ends in these proviral clones. It is possible that a fraction of transcripts fail to read through either the whole proviral sequence (for $5^{\prime}$ LTR transcription) or vector sequence (for $3^{\prime}$ LTR transcription). Even so, we notice that there is a consistently lower yield of these $3^{\prime}$ transcripts for vector versus viral transcription, which is again compatible with the activity of the 3' LTR poly(A) site on 3' LTR-initiated transcripts. However, the final experiment shown in Figure $6 \mathrm{D}$ provides perhaps the most compelling evidence. For the $\mathrm{pH}$ and $\mathrm{pH} 3$ 'S transcripts (Fig. 6D, lanes 1,2), the 
level of the $3^{\prime}$ LTR promoter-derived 127-nucleotide fragment increases for $\mathrm{pH}^{\prime} \mathrm{S}$ as compared with $\mathrm{pH}$, whereas the level of the 98-nucleotide fragment decreases by an equivalent amount. As the 98-nucleotide fragment arises from poly(A) site use directly downstream of the HIV-1 $3^{\prime}$ LTR promoter, it follows that when SPA is immediately downstream of the $3^{\prime}$ LTR promoter it competes with the HIV-1 poly(A) signal resulting in an increase in the ratio of 127-nucleotide (readthrough) to 98-nucleotide [HIV-1 poly(A) use] fragments.

The combined evidence from these different experiments strongly suggests that cleavage and polyadenylation occurs directly downstream of the 3' LTR promoter from which transcription is initiated. Quantitation of the level of poly(A) use reveals that $85 \%$ polyadenylation occurs at this site. This novel finding has obvious implications for the mechanism of poly(A) site selection in HIV-1.

\section{The effects of splicing on promoter-proximal polyadenylation}

The fact that polyadenylation occurs directly downstream of the initiating promoter in the $3^{\prime}$ but not at the 5 ' LTR suggests that sequences outside the identical LTRs contribute to poly(A) site regulation. The major splice donor site is situated immediately downstream of the 5' LTR. Therefore, we decided to investigate whether splicing or the presence of a splice donor site was responsible for the difference between the poly|A) site use in the two LTRs.

The first approach was to investigate whether poly(A) site use immediately downstream of the initiating $3^{\prime}$ LTR promoter was affected by the insertion of an intron in an analogous position to the intron found downstream of the 5' LTR. The intron used is derived from the tropomyosin $\alpha$ gene between exons 2 and 3 . The wild-type intron is inactive, which allows for gene regulation via alternative splicing. However, the insertion of a 23-nucleotide spacer region has been shown to activate the intron allowing efficient splicing (Smith and Nadal-Ginard 1989|. Therefore, the 23-nucleotide spacer intron and an inactive intron in which the splice donor has been removed were placed downstream of the $3^{\prime}$ LTR in the $\mathrm{pH}$ clone to give the constructs $\mathrm{pH} 3^{\prime} \alpha \mathrm{T} 2 / 3$ (active) and $\mathrm{pH} 3^{\prime} \alpha \mathrm{T} 2 / 3$ (inactive), respectively, as shown in Figure $7 \mathrm{~A}$.

Figure 7B shows the RNase protection using the $3^{\prime}$ LTR riboprobe. The identity of the protected fragments for all the constructs is as for $\mathrm{pH}$ (Fig. 6D), as the intron insertions are outside the probed region. Figure 7B, lane 1 , shows the $\mathrm{pH}$ construct in which, as described previously, the $5^{\prime}$ end of vector transcripts are denoted by the 98-nucleotide fragment and the 127-nucleotide fragment. The 98-nucleotide fragment represents transcripts that are polyadenylated immediately downstream of the initiating $3^{\prime}$ LTR promoter, and the 127-nucleotide fragment represents readthrough of this poly(A) site. The ratio of poly(A) site use to readthrough is 5.7. When SPA is placed downstream of the $3^{\prime}$ LTR as shown in lane 2, the ratio decreases dramatically to 0.5 . When the active intron is placed downstream (see lane 3 ) this ratio is 2.3 , indicating that the insertion of an intron has allowed a greater degree of poly(A) site readthrough. This ratio of 2.3 may be an overestimate, as the transcripts that read through the 3' LTR poly(A) site may be less stable as they have no poly $(\mathrm{A})$ site available until they read around the vector to the 5' LTR. Consistent with this hypothesis, we note that the level of the 98-nucleotide band as compared with the 96-nucleotide band /which derives from 5' LTR-initiated transcription) decreases to a similar level in both lanes 2 and 3. Finally, the insertion of the inactive intron gives a similar ratio to $\mathrm{pH}$ (lane 4).

To test whether the $5^{\prime}$ LTR poly(A) site is inactive in viral transcripts because of the downstream major splice donor site, a construct, $\mathrm{pH}$ MuMSD, was made where this splice donor was mutated at the splice junction from GU to CA (Fig. 7C). This mutation has been shown previously to inhibit intron splicing and may cause the use of an inefficient cryptic splice donor site at position 747 (Purcell and Martin 1993).

As before, to allow the detection of possible poly $(\mathrm{A})$ site fragments, the $\triangle \mathrm{PB}$ construct was used, which inactivates 3' LTR transcription. The RNase protection for this construct using the $5^{\prime}$ LTR riboprobe is shown in Figure $7 \mathrm{D}$, panel $\mathrm{I}$, and the identity of protected fragments is shown in Figure 7E. In figure 7D, panel 1, lane 1 shows $\mathrm{pH} \triangle \mathrm{PB}$ that has been described previously and predominantly gives the readthrough fragment (127 nucleotides). When pH $\Delta$ PB MuMSD was used, no steadystate transcripts were obtained (lane 2). This is presumably the result of the inhibition of splicing at the major splice donor site that abolishes production of mRNAs for early viral proteins such as Tat. The cotransfection of a Tat-producing plasmid restored these steady-state transcripts even though they were still lower than for $\mathrm{pH}$ (lane 3). This may be attributable to a squelching effect either by the cytomegalovirus (CMV) promoter that is used to drive Tat production or by the Tat protein itself. The key observation, however, is that a 96-nucleotide fragment that represents $5^{\prime}$ LTR promoter-proximal poly(A) site use is evident. Quantitation reveals that, depending on the transfection, $65 \%-80 \%$ of the total transcripts are processed at this site.

We, finally, wished to establish that the activation of the 96-nucleotide band in lane 3 truly reflects the addition of a poly(A) tail at this position. It was formally possible that this 96-nucleotide species could derive from the activation of a cryptic splice donor site at this position. Figure $7 \mathrm{C}$ shows the positions of reverse transcriptase-polymerase chain reaction (RT-PCR) primers used to detect this polyadenylated 5' LTR transcript. A $T_{12} \mathrm{~N}$ oligonucleotide was used to detect polyadenylated RNA by reverse transcription of $\mathrm{pH} \Delta \mathrm{PB}$ and $\mathrm{pH} \Delta \mathrm{PB}$ MuMSD + Tat-derived transcripts, and the cDNAs obtained were then amplified using a primer complementary to sequence immediately following the cap site position. This same oligonucleotide will also act as an antisense primer as a result of the TAR-inverted repeat 

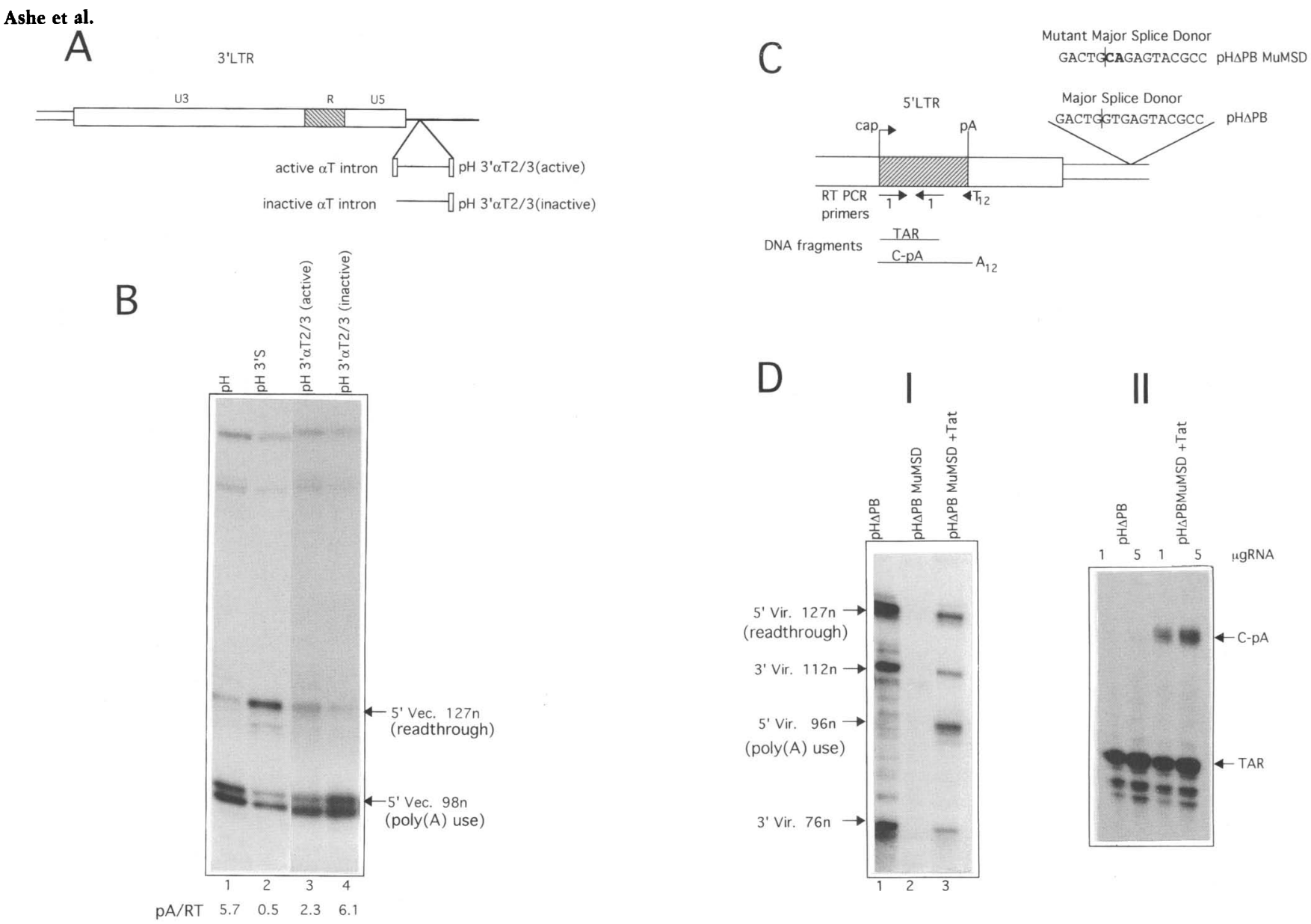

Figure 7. Upstream splicing inhibits promoter-proximal polyadenylation. (A) The diagram represents the $\mathrm{pH} 3^{\prime} \alpha \mathrm{T} 2 / 3$ (active) and $\mathrm{pH} 3^{\prime} \alpha \mathrm{T} 2 / 3$ (inactive) constructs. The $3^{\prime}$ LTR alone is shown, and the U3, R, and U5 regions are labeled. The intron is represented as a line between two small boxes that represent the splice donor and acceptor sites. For the mutant intron, only a splice acceptor box is shown as the splice donor has been deleted. $(B)$ RNase protection for the constructs $\mathrm{pH}, \mathrm{pH}^{\prime} \mathrm{S}$, and those described above. The construct names are shown at the top, and relevant protected fragments are labeled at right. The identities of the other fragments are shown in Fig. 6C,D. The ratio of 3' LTR promoter-proximal poly(A) site use to readthrough is shown at the bottom. This quantitation is based on several experiments that give similar results. $(C) \mathrm{A}$ diagram representing the $5^{\prime}$ LTR and major splice donor site of the pHAPB and pH $\triangle \mathrm{PB}$ MuMSD constructs (see Fig. 5A for the 3' LTR $\triangle \mathrm{PB}$ deletion). The LTR is shown as a large open rectangle, with hatching representing the $\mathrm{R}$ region. The cap, poly(A) site, and major splice donor site are also shown. The exact sequence of the major splice donor site and the precise 2-nucleotide mutation are shown at the top, where the mutated nucleotides are depicted in boldface type. Also, the positions of the RT-PCR primers are indicated. $(D) I$ shows the RNase protection for the $\mathrm{pH} \triangle \mathrm{PB}$ and $\mathrm{pH} \Delta \mathrm{PB}$ MuMSD constructs using a $5^{\prime}$ LTR riboprobe (see Fig. 3A). The construct names are at the top, and the cotransfection of a Tat-producing plasmid (pOGS213) for the pHAPB MuMSD clone is shown with the construct name. The protected fragments are labeled to the right and are as in Fig. 6E. Those fragments representing 5' LTR promoter-proximal poly(A) site use or readthrough are specifically labeled. $(D) I I$ represents RT-PCR products obtained for the same RNAs as in $I$. Primer 1 was 5 ' end labeled, and the products obtained were detected by autoradiography of denaturing PAGE. The TAR band derives from PCR amplification with primer 1 alone, whereas the C-pA band corresponds to RNA transcripts polyadenylated at the $5^{\prime}$ LTR poly(A) site. $(E)$ A diagram showing the identification of the protected fragments for the pHAPB-based constructs using a $5^{\prime}$ LTR riboprobe (see Fig. 3A). Arrangement as is in Fig. 3A, and those fragments representing $5^{\prime}$ LTR promoter-proximal poly(A) site use or readthrough are specifically labeled.

sequence. As shown in Figure 7D, panel II, a strong TAR product is present in all lanes. However, the cap-poly(A) band is only detected when the major splice donor site is mutated. This result clearly demonstrates that the poly(A) signal in the $5^{\prime}$ LTR has been activated. The fact that this poly $(\mathrm{A})$ band increases in strength with increased input RNA suggests that the PCR reaction was semiquantitative. We note that a trace amount of this band is detectable with pH $\triangle \mathrm{PB} R \mathrm{RNA}$, suggesting that a very low level of 5' LTR polyadenylation may occur in 
wild-type HIV-1 although this is not detectable using riboprobes.

\section{Discussion}

In this paper we have made a total of 20 proviral clones that allow us to analyze the relative contributions of different potential mechanisms that regulate HIV-1 poly(A) site use. The transient transfection of proviral clones in HeLa cells has been shown to faithfully mimic the infection of peripheral blood mononuclear cells with HIV-1 at the RNA level (Purcell and Martin 1993). Using this system, we have shown that the $5^{\prime}$ LTR, promoterproximal poly(A) site is essentially inactive and that the promoter-distal poly(A) site downstream of the viral genes is utilized exclusively. The inactivity of the proximal poly(A) site in the $5^{\prime}$ LTR is not the result of some fundamental mechanistic restraint, as the process of polyadenylation can occur at this position using SPA. The HIV-1 poly(A) site directly downstream of the initiating $3^{\prime}$ LTR promoter is fully active. Furthermore, when the major splice donor site is mutated, the $5^{\prime}$ LTR promoter-proximal poly(A) site also is activated. At the distal HIV-1 poly(A) site, downstream of the viral genes, we demonstrate that processing is efficient even when a series of previously described poly(A) site activating sequences are mutated. However, these mutations do show a decrease in the efficiency of the HIV-1 poly(A) site by a competition analysis, in agreement with previous results. Even so, in the absence of competition this decreased efficiency did not convert to a decrease in the levels of processed mRNAs.

The fact that the 3' LTR promoter-proximal poly(A) site was used efficiently whereas the $5^{\prime}$ LTR poly(A) site was not used in the HIV-1 proviral clones suggested that the presence of a downstream intron may effect polyadenylation. We investigated this possibility and, strikingly, the 5' LTR poly(A) site was activated when the major slice donor site was mutated. On the basis of these results we suggest that the predominant mechanism controlling the use of the poly(A) site in the HIV-1 provirus is centred around a specific readthrough of the $5^{\prime}$ LTR promoter-proximal poly(A) site that is determined by the presence of a downstream intron. The U3 activatory RNA sequences in the 3' LTR may also play a role in the biology of the virus by preventing readthrough of the $3^{\prime}$ LTR poly(A) site when proviral insertion occurs upstream of an efficient host genomic processing signal [either poly(A) or splicing signals].

\section{Promoter use in proviral clones}

Our results demonstrate that for a proviral clone, where the proviral DNA is contained in a circular plasmid, transcription not only occurs from the promoter upstream of the viral genes to the poly $(A)$ site downstream of the viral genome, but also occurs from the promoter downstream of the viral genes through vector sequences to the poly(A) site upstream of the viral genome. Similar results, where the transcriptional activity of the down- stream promoter has been detected, have been found using proviral plasmids, integrated virus, and duplicate isolated LTRs on circular plasmids (Eggermont and Proudfoot 1993; Klaver and Berkhout 1994). However, in previous studies using proviral plasmids, transcription from the $5^{\prime}$ LTR promoter was found to be predominant (Klaver and Berkhout 1994). This in turn agrees with the situation for Rous sarcoma virus (Cullen et al. 1984), avian leukosis virus (ALV) (Herman and Coffin 1986), and chicken syncytial virus (Boerkoel and Kung 1992). In our studies using HIV-1 proviral plasmids we found the level of initiation was almost identical from both promoters. This agrees with a previous study from our laboratory where isolated LTRs on plasmids gave identical levels of transcription (Eggermont and Proudfoot 1993). Most analyses do not directly measure the level of initiation at the promoter but use indirect means such as the level of downstream reporter genes or Northern analyses probing for downstream sequences. However, in this study, a method for distinguishing between transcripts initiated at either LTR has been developed, and this may detect transcription not detected by other assays using HIV-1 proviral clones. For example, the $3^{\prime}$ LTR promoter-derived 98-nucleotide fragment that derives from polyadenylation at the $3^{\prime}$ LTR poly(A) site would not be detected by any of the previous assays mentioned.

A number of groups have shown previously that placing a poly(A) site between two identical LTRs causes an increase in use of the downstream promoter and a decrease in use of the upstream promoter (Cullen et al. 1984; Eggermont and Proudfoot 1993). The results from this study agree with this conclusion because when an efficient poly(A) site is placed at the homologous position or 250 nucleotides farther downstream of this between $5^{\prime}$ and $3^{\prime}$ LTRs, a decrease in the ratio of $5^{\prime}$ to $3^{\prime}$ LTR-initiated transcription was seen. In addition, the shift in promoter use appeared to be related to the efficiency of the poly $(A)$ site because when inefficient poly (A) sites were used, the change in promoter use was much less. Furthermore, this was not related to a direct effect on the transcription from the $5^{\prime}$ LTR promoter because when the $3^{\prime}$ LTR promoter was inactivated, little difference in levels of $5^{\prime}$ LTR promoter fragments was detected. This is consistent with the poly(A) site acting to relieve a transcriptional interference effect between the two LTRs. However, when an efficient poly(A) site was placed downstream of the $3^{\prime}$ LTR promoter in the construct $\mathrm{pH} 3$ 'S, no change in the ratio of the promoters was detected. This is possibly because efficient polyadenylation is already occurring at the 3 ' LTR HIV-1 poly(A) site directly downstream of the 3' LTR promoter. This means that an additional poly(A) site, such as SPA, placed downstream will have little effect on the ratio of promoter use. It does, however, effect the ratio of poly(A) site use.

\section{$\operatorname{Poly}(A)$ site use and exon definition}

The experiments in this study show that accurate $3^{\prime}$-end formation is possible immediately downstream of the 
promoter. Previously, it has been speculated that these short polyadenylated transcripts may exist but are not stably transported from the cytoplasm. Each of the short polyadenylated transcripts in this study, however, are quite similar to the short transcripts generated from the HIV-1 promoter in the absence of Tat (Laspia et al. 1989). These Tat-independent short transcripts are very efficiently transported to the cytoplasm, and it is therefore possible that the short polyadenylated transcripts described here follow a similar nuclear pathway. Preliminary evidence suggests that the short polyadenylated transcript is more prevalent in the cytoplasm than the nucleus (data not shown). In addition, neither intron splicing nor a 3' splice acceptor site are requirements for the process of polyadenylation of mRNAs. Previously, it has been shown in vitro and in cell culture assays that either the presence of an intron or a 3 ' splice acceptor site upstream of the poly(A) sequence increases the efficiency of 3'-end formation (Niwa et al. 1990; Chiou et al. 1991, Wasserman and Steitz 1993; Nesic et al. 1993; Nesic and Maquat 1994). This information was used to formulate a theory of exon definition where for efficient 3 '-end formation, the $5^{\prime}$ end of the exon must be defined (Niwa et al. 1992). Although our results are not consistent with the requirement for a splice acceptor or an intron for efficient 3 '-end formation, they are consistent with the theory of exon definition, only in this case, the $5^{\prime}$ end of the first exon is defined by the cap site and the $3^{\prime}$ end of this exon is defined by the $\operatorname{poly}(A)$ site.

\section{Possible mechanisms for $\operatorname{poly}(A)$ site inhibition as a result of a downstream intron}

This study was designed to analyze which of the proposed models that have been detailed by a number of groups is the predominant mechanism by which HIV-1 poly(A) site use is regulated using a proviral system. Our results suggest that for a proviral clone the specific readthrough of the poly(A) site downstream of the $5^{\prime}$ LTR promoter is a major contributor to poly(A) site selection. The mechanism by which this readthrough is achieved appears to involve the presence of a downstream intron.

The efficiency of splicing at the major splice donor site is an important consideration when the mechanistic implications of these results are considered. In similar studies using proviral clones where RNA was harvested $48 \mathrm{hr}$ after transfection, splicing at the major splice donor site was shown to be inefficient. Of the HIV-1 RNA, 60\%$70 \%$ remains unspliced (Felber et al. 1989; Amendt et al. 1994). Using our system, a similar level of splicing at the major splice donor site is detected (data not shown). Therefore, it seems unlikely that inhibition of the $5^{\prime}$ LTR poly(A) site is the result of competition with downstream splicing events. Alternatively, it may not be the process of intron splicing that affects polyadenylation but the process of splice donor site recognition. The inefficient splicing of HIV-1 RNAs has been explained by the weakness of the splice acceptor sites, either because they do not conform to the consensus splice acceptor site sequence or because of inhibitor sequences (Amendt et al. 1994). Therefore, the interaction at the splice donor site is potentially an efficient process. The $\mathrm{U} 1 \mathrm{small} \mathrm{nu}-$ clear ribonucleoprotein (snRNP) binds to the splice donor site as one of the first steps in spliceosome assembly. It is possible that this interaction is responsible for the inhibition of cleavage and polyadenylation at the upstream poly(A) site.

It has been demonstrated previously that the presence of an upstream splice donor site can inhibit polyadenylation at a downstream poly(A) site (Wasserman and Steitz 1993; Furth et al. 1994). However, in the case of HIV-1, the splice donor site lies downstream of the poly(A) site, and in at least one of the systems mentioned above, the papillomavirus late poly(A) site, the insertion of the inhibiting splice donor site downstream of the poly(A) site has little effect (Furth and Baker 1991). The reason for this variation may be differences in the efficiency of the processing signals involved or may hint at a different molecular mechanism for the two effects.

For the papillomavirus inhibitory splice donor sequence, it has been demonstrated that $\mathrm{Ul}$ interaction is critical for poly(A) site inhibition (Furth et al. 1994). Similarly, for HIV-1 the recognition of the major splice donor site by the UlsnRNP may be responsible for the inhibition. The U1 snRNP may simply occlude 3 '-end formation by the steric hindrance of interactions required for polyadenylation. Alternatively, the U1A protein, which forms part of the U1 snRNP, may repress polyadenylation. Interestingly, free U1A protein has been shown to inhibit polyadenylation from an upstream location in the U1A transcript via inhibition of the poly(A) polymerase (Boelens et al. 1993; Gunderson et al. 1994). It is possible that this protein may have a similar effect here, thereby inhibiting upstream cleavage and polyadenylation. However, the same U1A protein has been shown to activate polyadenylation as part of the U1 snRNP from upstream of the SV40 late poly(A) site (Lutz and Alwine 1994).

The results presented in this study graphically demonstrate that the mRNA processing mechanisms of splicing and polyadenylation may directly influence each other. Although it has been reported in several different situations that poly(A) site recognition does not occur efficiently when in an intronic location (Levitt et al. 1989; Furth et al. 1994; Peterson 1994l, this study represents the first description of a splice donor site that directly inhibits the use of an upstream poly(A) site in a preceding exon.

\section{Materials and methods}

\section{Plasmid construction}

Plasmid $\mathrm{pH}$ was constructed using the proviral plasmid pNL4-3 (Adachi et al. 1986). The two LTR sequences were amplified separately using PCR. The 5' LTR was amplified using an LTRspecific sense primer that also placed an AscI site at the extreme $5^{\prime}$ end of the LTR and an antisense primer where the $5^{\prime}$ end is the NarI site at position 638 . The 3' LTR was amplified using a sense primer, where the $5^{\prime}$ end is the BamHI at position 8466 , 
and an antisense primer, where the $5^{\prime}$ end creates an $A s c$ I site that adds on to the extreme $3^{\prime}$ end of the $3^{\prime}$ LTR. Using the resulting fragments and the NarI-BamHI fragment from between the two LTRs, the provirus was reconstructed in a pUC19 vector (Vieira and Messing 1982). The resulting plasmid $\mathrm{pH}$ has the $5^{\prime}$ LTR positioned at 56 of pUC19 (numbering as in New England Biolabs catalog, 1994) fused at the NarI site to the NarIBamHI fragment, which then has the 3' LTR PCR fragment ending at $\mathrm{BamHI}$ in the pUC19 polylinker. Therefore, this creates the NL4-3 provirus flanked by AscI sites in pUC19 and removes all flanking sequences from pNL4-3.

The plasmid pH5'S is identical to $\mathrm{pH}$, except a BamHI-KpnI blunt-ended fragment from pySPA - (Enriques-Harris et al. 1991) containing SPA sequences replaces the 5' LTR HIV-1 poly(A) site that was removed using $A f l I I$ and HinfI sites that flank it.

The plasmids $\mathrm{pHS}+/-$ and $\mathrm{pHH}+$ were constructed by placing blunt-ended poly(A) site fragments into the BssHII site at position 712. The HIV-1 poly(A) site fragment is a blunt-ended BgIII-BamHI fragment from the plasmid pSP65HIVAH (Weichs an der Glon et al. 1991), and the SPA fragment is a blunt-ended $B a m H I-E c o$ RI fragment from pySPA -. The $\triangle \mathrm{PB}$ derivatives were made by replacing the $3^{\prime}$ LTR with that from $\mathrm{pH} \Delta \mathrm{PB}$ using a BamHI site.

The plasmid pH $\Delta \mathrm{U} 3$ was made using the two BglII sites at 9042 and 9548 to delete the entire U3 sequence. pH $\Delta \mathrm{PB}$ was made by using a PvuII at 9510 and a blunt-ended BgIII site at 9548 followed by religation. This plasmid was then used to make all the $\triangle \mathrm{PB}$ clones by direct replacement of the $3^{\prime}$ LTR using BamHI sites at 8466 and in the pUC19 polylinker. The $\mathrm{pH}$ Linker plasmid was made using the same $P_{V u I I}-B g I I I$ sites and replacing the intervening sequence with an oligonucleotide linker. The sequences of the oligonucleotides used are 5'- GACAAAAACGGACATGACCCAGAGAGACCAATGACCA-3' and 5'-GATCTGGTCATTGGTCTCTCTGGGTCATGTCCGTTTTTCGTC-3',

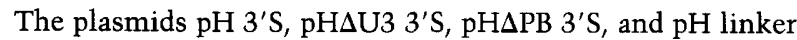
$3^{\prime} \mathrm{S}$ were made by placing a blunt-ended $B a m H I-E c o$ RI fragment from pySPA - into the blunt-ended $\mathrm{XbaI}$ site of the polylinker of $\mathrm{pH}, \mathrm{pH} \Delta \mathrm{U} 3, \mathrm{pH} \Delta \mathrm{PB}$, and $\mathrm{pH}$ Linker, respectively.

The plasmid $\mathrm{pH} 3^{\prime} \alpha \mathrm{T} 2 / 3$ (active) was made by placing a blunt-ended StyI-PvuII fragment of the $\alpha$-tropomyosin sequence (a gift from $\mathrm{C}$. Smith, University of Cambridge, $\mathrm{UK}$ ) into the blunt-ended $X b a I$ site of $\mathrm{pH}$. $\mathrm{pH} 3^{\prime} \alpha \mathrm{T} 2 / 3$ (inactive) was made similarly, only here the fragment used was a blunt-ended KpnI-PvuII.

The plasmid pHAPB MuMSD was made using a PCR mutagenesis technique described by Picard et al. (1994), using a mutant oligonucleotide where GU at position 743 was changed to $\mathrm{CA}$.

The plasmids used to make riboprobes were made using pGEM7-Zf vectors. For the 3' LTR riboprobe, the AvaI-HinfI section of the $3^{\prime}$ LTR PCR fragment was placed in $X b a$ I to give pG7f $|+|$ 3'AH. This plasmid was linearized using EcoRI for riboprobe production. For the $5^{\prime}$ LTR riboprobe, the same piece of the $5^{\prime}$ LTR PCR fragment was placed in HindIII to give pG7f( +) 5'AH, and for the 5' LTR SPA riboprobe, the AvaI-Narl fragment from a 5' LTR SPA intermediate clone was also placed at the HindIII site to give pG7f $|+| 5^{\prime} \mathrm{S}$, AN. For these two plasmids, linearized templates were made using the BamHI site.

\section{Transfection procedures}

Five micrograms of the various proviral plasmids were transfected into subconfluent HeLa cells by DNA/calcium phosphate precipitate. For the p24 assay, 200- $\mu 1$ media samples were taken at various time points up to $72 \mathrm{hr}$ post-transfection. At this time point, $\mathrm{C} 8166$ cells were cocultured with the HeLa cells and sampling was continued. C8166 cells were passaged every 3 days after this period with continued sampling to 13 days post-transfection. Additionally, for the RNA analysis, $3 \mu \mathrm{g}$ of a plasmid that produces the human $\beta$-globin mRNA, $p \beta E$ (Proudfoot et al. 1992), and where indicated, $3 \mu \mathrm{g}$ of a plasmid that produces Tat protein, pOGS213 (Adams et al. 1988), were transfected; cytoplasmic RNA was harvested after $48 \mathrm{hr}$ (for a more detailed method, see Eggermont and Proudfoot 1993).

\section{p24 assay}

The production of HIV-1 virions in the culture supernatants of transfected cells was determined as described previously (Simon et al. 1993). Briefly, samples of culture supernatant were clarified by low-speed centrifugation, inactivated by heat treatment $\left(56^{\circ} \mathrm{C}\right.$ for $\left.30 \mathrm{~min}\right)$ in the presence of Empigen detergent $10.1 \%$ $\mathrm{vol} / \mathrm{vol}$. HIV-1 p 24 capsid protein in the samples was detected using a sandwich capture ELISA in which an affinity-purified sheep anti-p24 peptide antiserum was used to capture the antigen and a biotinylated monoclonal anti-p24 antibody together with streptavidin-alkaline phosphatase was used for detection. Each plate was calibrated using Baculovirus-expressed HIV-1 p24.

\section{RNA analysis}

A fifth of the RNA was used for $3^{\prime}$-end mapping of the human $\beta$-globin mRNA (to serve as a cotransfection control) using an end-labeled $E c o$ RI fragment of $\mathrm{p} \beta E$ as a probe for $\mathrm{S} 1$ nuclease protection. Specifically, 50 counts per sec of probe was annealed to cytoplasmic RNA in R loop buffer $180 \%$ deionized formamide, $40 \mathrm{~mm}$ PIPES at $\mathrm{pH} 6.4,1 \mathrm{~mm}$ EDTA at $\mathrm{pH} 8.0$, and $400 \mathrm{~mm}$ $\mathrm{NaCl})$ at $52^{\circ} \mathrm{C}$. This was then diluted with S1 buffer $[250 \mathrm{~mm}$ $\left.\mathrm{NaCl}, 30 \mathrm{~mm} \mathrm{NaOAc}, 2 \mathrm{~mm} \mathrm{Zn}(\mathrm{OAc})_{2}, \mathrm{pH} 4.6\right]$ plus enzyme. The digested DNA was purified, fractionated by polyacrylamide gel electrophoresis, and visualized by autoradiography.

The same RNA was used for RNase protection analysis. The plasmids used to make the riboprobes were linearized and $0.5 \mu \mathrm{g}$ of linearized template was in vitro transcribed in the presence of $\left[\alpha-{ }^{32} \mathrm{P}\right] \mathrm{CTP}$ or $\left[\alpha^{-32} \mathrm{P}\right] \mathrm{UTP}(800 \mathrm{Ci} / \mathrm{mmole})$ with (Promega) T7 RNA polymerase according to the manufacturer's instructions. The riboprobe was digested with DNase I and RNase-free (Boehringer Mannheim/ and purified. $500 \mathrm{cps}$ of probe was annealed to a fifth of the RNA in R loop buffer at $56^{\circ} \mathrm{C}$, and this was diluted with RNase protection buffer ( $10 \mathrm{mM}$ Tris at $\mathrm{pH} 7.5,5$ mM EDTA, $300 \mathrm{~mm} \mathrm{NaCl})$, RNase A $(40 \mu \mathrm{g} / \mathrm{ml})$, and RNase Tl $(1000 \mathrm{U} / \mathrm{ml})$. RNase digestion was performed for $2 \mathrm{hr}$ at $18^{\circ} \mathrm{C}$, followed by proteinase $\mathrm{K}$ treatment, phenol/chloroform extraction, and ethanol precipitation. The resultant RNase-digested RNA was fractionated by electrophoresis and visualized by autoradiography. The electrophoresis gels were quantitated using a PhosphorImager, and this was checked using laser densitometry of autoradiographs. Protected fragments were assigned using different riboprobes on the basis of size versus denatured DNA markers.

The RT-PCR analysis described in Figure 6 was carried out as follows: Cytoplasmic RNA (1 or $5 \mu \mathrm{g}$ ) was reverse-transcribed with GAATTCT ${ }_{12} \mathrm{C} / \mathrm{A} / \mathrm{G}$ and then amplified to 30 cycles with kinase-labeled $\left(5^{\prime 32} \mathrm{p}\right)$ primerl (GGGTCTCTCTGGTTAGACCAGATCT) using Taq polymerase under standard conditions. The ${ }^{32} \mathrm{P}$-labeled PCR products obtained were fractionated on a denaturing polyacrylamide gel. 


\section{Acknowledgments}

We thank C. Birse, H. White, and S. Brackenridge for critical reading of the manuscript and S. Murphy, T. Humphrey, C. Birse, B. Lee, and H. White for their help. In addition, we thank S. Kingsman and C. Smith for the gift of plasmids and A. Newman for his advice. This work has been supported by a Wellcome Programme (032773) and a Medical Research Council (MRC) Aids Directed Project (ADP) (G931072) grant to N.J.P. M.P.A. was supported by an MRC-ADP Research Studentship.

The publication costs of this article were defrayed in part by payment of page charges. This article must therefore be hereby marked "advertisement" in accordance with 18 USC section 1734 solely to indicate this fact.

\section{References}

Adachi, A., H.E. Gendelman, S. Koenig, T. Folks, R. Willey, A. Rabson, and M.A. Martin. 1986. Production of acquired immunodeficiency syndrome-associated virus in human and nonhuman cells transfected with an infectious molecular clone. J. Virol. 59: 284-29l.

Adams, S.E., I.D. Johnson, M. Braddock, A.J. Kingsman, S.M. Kingsman, and R.M. Edwards. 1988. Synthesis of a gene for the HIV transactivation protein TAT by a novel single stranded approach involving in vivo gap repair. Nucleic Acids Res. 16: 4278-4297.

Ahmed, Y.F., G.M. Gilmartin, S.M. Hanly, J.R. Nevins, and W.C. Greene. 1991. The HTLV-I rex response element mediates a novel form of mRNA polyadenylation. Cell 64: 727737.

Amendt, B.A., D. Hesslein, L.-J. Chang, and C.M. Stoltzfus. 1994. Presence of negative and positive cis-acting RNA splicing elements within and flanking the first tat coding exon of human immunodeficiency virus type 1. Mol. Cell. Biol. 14: 3960-3970.

Boelens, W.C., E.J.R. Jansen, W.J. van Venrooji, R. Stripecke, I.W. Mattaj, and S.I. Gunderson. 1993. The human U1 snRNP-specific U1A protein inhibits polyadenylation of its own pre-mRNA. Cell 72: 881-892.

Boerkoel, C.F. and H.-J. Kung. 1992. Transcriptional interaction between retroviral long terminal repeats (LTRs): Mechanism of $5^{\prime}$ LTR supression and 3'LTR promoter activation of $c$-myc in avian B-cell lymphomas. $I$. Virol. 66: 4814-4823.

Brown, P.H., L.S. Tiley, and B.R. Cullen. 1991. Efficient polyadenylation within the human immunodeficiency virus type 1 long terminal repeat requires flanking U3-specific sequences. I. Virol. 65: 3340-3343.

Carswell, S. and J.C. Alwine. 1989. Efficiency of utilization of the simian virus 40 late polyadenylation site: Effects of upstream sequences. Mol. Cell. Biol. 9: 4248-4258.

Cherrington, J. and D. Ganem. 1992. Regulation of polyadenylation in human immunodeficiency virus (HIV): Contributions of promoter proximity and upstream sequences. $E M B O$ I. 11: 1513-1524.

Cherrington, J., R. Russnak, and D. Ganem. 1992. Upstream sequences and cap proximity in the regulation of polyadenylation in ground squirrel hepatitis virus. I. Virol. 66: 75897596.

Chiou, H.C., C. Dabrowski, and J.C. Alwine. 1991. Simian virus 40 late mRNA leader sequences involved in augmenting mRNA accumulation via multiple mechanisms, including increased polyadenylation efficiency. I. Virol. 65: 66776685.

Cullen, B.R., T. Lomedico, and G. Ju. 1984. Transcriptional interference in avian retroviruses-Implications for promoter insertion model of leukaemogenesis. Nature 307: 241-245.

DeZazzo, J.D., J.E. Kilpatrick, and M.J. Imperiale. 1991. Involvement of long terminal repeat U3 sequences overlapping the transcription control region in human immunodeficiency virus type 1 mRNA $3^{\prime}$ end formation. Mol. Cell. Biol. 11: $1624-1630$.

DeZazzo, J.D., J.M. Scott, and M.J. Imperiale. 1992. Relative roles of signals upstream of AAUAAA and promoter proximity in regulation of human immunodeficiency virus type 1 mRNA $3^{\prime}$ end formation. Mol. Cell. Biol. 12: 5555-5562.

Dougherty, J.P. and H.M. Temin. 1987. A promoterless retroviral vector indicates that there are sequences in $\mathrm{U} 3$ required for 3' RNA processing. Proc. Natl. Acad. Sci. 84: 1197-1201.

Eckner, R., W. Ellmeier, and M.L. Birnstiel. 1991. Mature mRNA $3^{\prime}$ end formation stimulates RNA export from the nucleus. EMBO I. 10: 3513-3522.

Eggermont, J. and N.J. Proudfoot. 1993. Poly(A) signals and transcriptional pause sites combine to prevent interference between RNA polymerase II promoters. EMBO J. 12: 25392548.

Enriques-Harris, P., N. Levitt, D. Briggs, and N.J. Proudfoot. 1991. A pause site for RNA polymerase II is associated with termination of transcription. EMBO J. 10: 1833-1842.

Felber, B.K., M. Hadzopolou-Cladaras, C. Cladaras, T. Copeland, and G.N. Pavlakis. 1989. rev protein of human immunodeficiency virus type 1 affects the stability of the viral mRNA. Proc. Natl. Acad. Sci. 86: 1495-1499.

Feng, S. and E.C. Holland. 1988. HIV-1 tat trans-activation requires the loop sequences within tar. Nature 334: 165-167.

Furth, P.A. and C.C. Baker. 1991. An element in the bovine papillomavirus late $3^{\prime}$ untranslated region reduces polyadenylated cytoplasmic RNA levels. J. Virol. 65: 5806-5812.

Furth, P.A., W.-T. Choe, J.H. Rex, J.C. Byrne, and C.C. Baker. 1994. Sequences homologous to $5^{\prime}$ splice sites are required for the inhibitory activity of papillomavirus late $3^{\prime}$ untranslated regions. Mol. Cell. Biol. 14: 5278-5289.

Gilmartin, G.M., E.S. Fleming, and J. Oetjen. 1992. Activation of HIV-1 pre-mRNA 3 ' processing in vitro requires both an upstream element and TAR. EMBO $J$. 11: 4419-4428.

Gilmartin, G.M., E.S. Fleming, J. Oetjen, and B.R. Graveley. 1995. CPSF recognition of an HIV-1 mRNA 3'-processing enhancer: Multiple sequence contacts involved in poly(A) site definition. Genes \& Dev. 9: 72-83.

Gunderson, S.I., K. Beyer, G. Martin, W. Keller, W.C. Boelens, and I.W. Mattaj. 1994. The human U1A snRNP protein regulates polyadenylation via a direct interaction with poly $(\mathrm{A})$ polymerase. Cell 76: 531-541.

Herman, S.A. and J.M. Coffin. 1986. Differential transcription from the long terminal repeats of integrated avian leukosis virus DNA. J. Virol. 60: 497-505.

Hsieh, S.-Y. and J. Taylor. 1991. Regulation of polyadenylation of hepatitis delta virus antigenomic RNA. J. Virol. 65: 64386446.

Iwasaki, K. and H.M. Temin. 1990a. The U3 region is not necessary for 3 ' end formation of spleen necrosis virus RNA. $J$. Virol. 64: 6329-6334.

- $1990 \mathrm{~b}$. The efficiency of RNA $3^{\prime}$-end formation is determined by the distance between the cap site and the poly(A) site in spleen necrosis virus. Genes \& Dev. 4: 2299-2307.

Jackson, R.J. and N. Standart. 1990. Do the poly(A) tail and 3' untranslated region control mRNA translation? Cell 62: 1524.

Ju, G. and B.R. Cullen. 1985. The role of avian retroviral LTRs in the regulation of gene expression and viral replication. Adv. Virus Res. 30: 179-223.

Klaver, B. and B. Berkhout. 1994. Comparison of $5^{\prime}$ and $3^{\prime}$ long 
terminal repeat promoter function in human immunodeficiency virus. $J$. Virol. 68: 3830-3840.

Laspia, M.F., A.P. Rice, and M.B. Mathews. 1989. HIV-1 Tat protein increases transcriptional initiation and stabilizes elongation. Cell. 59: 283-292.

Levitt, N., D. Briggs, A. Gil, and N.J. Proudfoot. 1989. Definition of an efficient synthetic poly(A) site. Genes \& Dev. 3: 1019-1025.

Lutz, C.S. and J.C. Alwine. 1994. Direct interaction of the U1 snRNP-A protein with the upstream efficiency element of the SV40 late polyadenylation signal. Genes \& Dev. 8: 576586.

Manley, J.L. and N.J. Proudfoot. 1994. RNA 3' ends: Formation and function: Meeting review. Genes \& Dev. 8: 259-264.

Mann, K.P., E.A. Weiss, and J.R. Nevins. 1993. Alternative poly(A) Site utilization during adenovirus infection coincides with a decrease in the activity of a poly(A) site processing factor. Mol. Cell. Biol. 13: 2411-2419.

McLauchlan, J., A. Phelan, C. Loney, R.M. Sandri-Goldin, and J.B. Clements. 1992. Herpes simplex virus IE63 acts at the posttranscriptional level to stimulate viral mRNA $3^{\prime}$ processing. J. Virol. 66: 6939-6945.

Moreira, A., M. Wollerton, J. Monks, and N.J. Proudfoot. 1995. Upstream sequence elements enhance poly|A $\mid$ site efficiency of the $\mathrm{C} 2$ complement gene and are phylogenetically conserved. EMBO I. 14: 3809-3819.

Nesic, D. and L.E. Maquat. 1994. Upstream introns influence the efficiency of final intron removal and RNA $3^{\prime}$-end formation. Genes \& Dev. 8: 363-375.

Nesic, D., J. Cheng, and L.E. Maquat. 1993. Sequences within the last intron function in RNA 3 '-end formation in cultured cells. Mol. Cell. Biol. 13: 3359-3369.

Niwa, M., S.D. Rose, and S.M. Berget. 1990. In vitro polyadenylation is stimulated by the presence of an upstream intron. Genes \& Dev. 4: 1552-1559.

Niwa, M., C.C. MacDonald, and S.M. Berget. 1992. Are vertebrate exons scanned during splice-site selection? Nature 360: $277-280$.

Peterson, M.L. 1994. Regulated immunoglobulin (Ig) RNA processing does not require specific cis-acting sequences: NonIg RNA can be alternatively processed in B cells and plasma cells. Mol. Cell. Biol. 14: 7891-7898.

Picard, V., E. Ersdal-Badju, A. Lu, and S.C. Bock. 1994. A rapid and efficient one-tube PCR-based mutagenesis technique using Pfu DNA polymerase. Nucleic Acids Res. 22: 25872591.

Proudfoot, N.J. 1991. Poly(A) signals. Cell 64: 671-674.

Proudfoot, N.J., B.A. Lee, and J. Monks. 1992. Multiple Sp1 binding sites confer enhancer-independent, replication-activated transcription of HIV-1 and globin promoters. NeW Biol. 4: 369-381.

Purcell, D.F.J. and M.A. Martin. 1993. Alternative splicing of human immunodeficiency virus type 1 mRNA modulates viral protein expression, replication and infectivity. $J$. Virol. 67: 6365-6378.

Rothnie, H.M., Y. Chapdelaine, and T. Hohn. 1994. Pararetroviruses and retroviruses: A comparative review of viral structure and gene expression strategies. Adv, Virus Res. 44: $1-67$.

Russnak, R.H. 1991. Regulation of polyadenylation in hepatitis B viruses: Stimulation by the upstream activating signal PS1 is orientation-dependent, distance-dependent, and additive. Nucleic Acids Res. 19: 6449-6456.

Russnak, R. and D. Ganem. 1990. Sequences $5^{\prime}$ to the polyadenylation signal mediate differential poly(A) site use in hepatitis B viruses. Genes \& Dev. 4: 764-776.
Sachs, A.B. 1993. Messenger RNA degradation in eukaryotes. Cell. 74: 413-421.

Sanfaçon, H. and T. Hohn. 1990. Proximity to the promoter inhibits recognition of cauliflower mosaic virus polyadenylation signal. Nature 346: 81-84.

Sanfaçon, H., P. Brodmann, and T. Hohn. 1991. A dissection of the cauliflower mosaic virus polyadenylation signal. Genes \& Dev. 5: 141-149.

Simon, J.H.M., C. Samoza, G.A. Schockmel, M. Collin, S.J. Davis, A.F. Williams, and W. James. 1993. A Rat CD4 mutant containing the gp120-binding site mediates human immunodeficiency virus type 1 infection. I. Exp. Med. 177: 949-954.

Smith, C.W.J. and B. Nadal-Ginard. 1989. Mutually exclusive splicing of $\alpha$-tropomyosin exons enforced by an unusual lariat branch point location: Implications for constitutive splicing. Cell 56: 749-758.

Valsamakis, A., S. Zeichner, S. Carswell, and J.C. Alwine. 1991. The human immunodeficiency virus type 1 polyadenylation signal: A 3' long terminal repeat element upstream of the AAUAAA necessary for efficient polyadenylation. Proc. Natl: Acad. Sci. 88: 2108-2112.

Valsamakis, A., N. Schek, and J.C. Alwine. 1992. Elements upstream of the AAUAAA within the human immunodeficiency virus polyadenylation signal are required for efficient polyadenylation in vitro. Mol. Cell. Biol. 12: 3699-3705.

Vieira, J. and J. Messing. 1982. The pUC plasmids, an M13mp7derived system for insertion mutagenesis and sequencing with synthetic universal primers. Gene 19: 259-268

Wahle, E. and W. Keller. 1992. The biochemistry of 3' end cleavage and polyadenylation of messenger RNA precursors. Annu. Rev. Biochem. 61: 419-440.

Wasserman, K.M. and J.A. Steitz. 1993. Association with terminal exons in pre-mRNAs: A new role for the Ul snRNP? Genes \& Dev, 7: 647-659.

Weichs an der Glon, C., J. Monks, and N.J. Proudfoot. 1991. Occlusion of the HIV poly(A) site. Genes \& Dev. 5: 244-253.

Weichs an der Glon, C., M. Ashe, J. Eggermont, and N.J. Proudfoot. 1993. Tat-dependent occlusion of the HIV poly(A) site. EMBO I. 12: 2119-2128.

Zenzie-Gregory, B., P. Sheridan, K.A. Jones, and S.T. Smale. 1993. HIV-1 core promoter lacks a simple initiator element but contains a bipartite activator at the transcription start site. J. Biol. Chem. 268: 15823-15832. 




\section{Poly(A) site selection in the HIV-1 provirus: inhibition of promoter-proximal polyadenylation by the downstream major splice donor site.}

M P Ashe, P Griffin, W James, et al.

Genes Dev. 1995, 9:

Access the most recent version at doi:10.1101/gad.9.23.3008

References This article cites 64 articles, 37 of which can be accessed free at:

http://genesdev.cshlp.org/content/9/23/3008.full.html\#ref-list-1

License

Email Alerting Receive free email alerts when new articles cite this article - sign up in the box at the top Service right corner of the article or click here.



Focused on your science. 